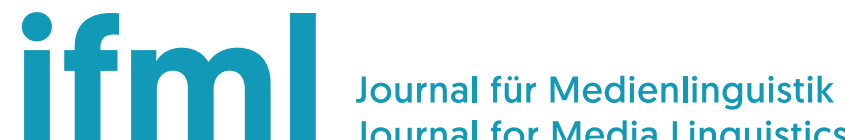 \\ Journal for Media Linguistics
}

Vol 4 (2021), No 2: 123-161

DOI: $10.21248 / \mathrm{jfml} .2021 .33$

Discussion paper available at: http://dp.jfml.org/2020/opr-baldauf-quilliatre-colon-de-carvajal-doingparticipation-non-players-participating-in-video-gaming/

\section{Spectating: How non-players participate in videogaming}

Heike Baldauf-Quilliatre \& Isabel Colón de Carvajal

\begin{abstract}
This paper investigates situations in French videogame interactions where non-players who share the same physical space as players, participate in the gaming activities as spectators. Through a detailed multimodal and sequential analysis, we show that being a spectator is a local achievement of all co-present participants - players and non-players. Our argument is twofold. Firstly, we focus on three gaming interactions and connect the different configurations to the non-players' participation practices. We analyse the development of the game, watching, commenting, gaze and body movements of players and non-players, as well as the configuration of the spatial environment are intertwined. Three different "ways of spectating" are identified: doing being a couple, doing being friends and doing being a supporter. Additionally, we describe a selection of embodied practices used to locally achieve these "ways of spectating", indicating that spectatorship is co-constructed.
\end{abstract}

Keywords: conversation analysis, videogames, screen-based interaction, participation framework, non-players, ways of spectating, spectating, relationships

Corresponding authors:

$\begin{array}{rr}\begin{array}{r}\text { Heike Baldauf-Quilliatre } \\ \text { Université Lyon 2 Lumière, }\end{array} & \begin{array}{r}\text { Isabel Colón de Carvajal } \\ \text { ENS de Lyon, ICAR (UMR }\end{array} \\ \text { ICAR (UMR 5191) } & \text { 5191), isabelle.colonde } \\ \text { heike.baldauf@univ-lyon2.fr } & \text { carvajal@ens-lyon.fr } \\ \text { Postal address: } & \\ \text { Ecole Normale Supérieure de Lyon - Site Descartes } \\ \text { Interactions, Corpus, Apprentissages, Représentations (ICAR) } \\ \text { 15, Parvis René Descartes } \\ \text { BP 7000 } \\ 69342 \text { LYON cedex } 07 \text { (France) }\end{array}$




\section{Introduction}

Participation in interaction is not a categorical straightforward engagement but rather an interactional achievement and a locally accomplished practice (cf. Goodwin/Goodwin 2004). Additionally, the focus on multi-activity and/or multi-tasking in the last decade has highlighted the possibility of being engaged more or less simultaneously in different activities and therefore, of showing different and simultaneous practices of participation.

Despite the large number of interactional studies dealing with participation framework in different settings, the construction of "spectatorship" has been less explored. In our data of French videogame interactions, some of the co-present participants are not playing. In most of our settings, friends or family members take turns in playing. The current non-players might then engage in other activities (getting food or drinks, reading, chatting with other non-players) while they watch the game (or not). When they watch the game, they become spectators or even co-players who contribute consequentially to the unfolding gaming actions (see Olbertz-Siitonen/Piirainen-Marsh/Siitonen in this issue).

By looking more closely at the notion of spectating/spectator, at what people do as spectators and how the different actions are related to the gaming activity, we want to explore what spectating means in this case and for the participants. We follow an interactional approach and show that and how spectating is an interactional achievement. The first part of our analysis highlights how the participants establish the role of spectator whilst at the same time doing social relationships. The second part focuses in more detail on the local multimodal accomplishment of participation as spectator and on different embodied practices.

\section{Spectators in interaction}

So far, media linguistics research on spectators has mostly focused on the unilateral reception of media contents. Few studies took into account the interaction between spectators and the way they appropriate media content or use media interactively (cf. Holly/Püschel/ Bergmann 2001; Gerhardt 2006). These studies draw on recordings of viewers (spectators) watching television together and interacting simultaneously with each other. Videogame interactions in our data are similar to these spectating interactions in several ways: 
- the participants focus on a screen and a large part of their interaction is related to what happens on screen.

- the participants are engaged in at least two different types of activities: watching and interacting.

They differ in that some of the participants directly intervene in the screen events (players) while others do not (non-players). This has direct consequences on the activities of watching and interacting. The non-players:

- can watch the screen as well as the players who act on the screen.

- cannot act directly in the game, but they can interact with the players and indirectly influence what happens in the game.

From an interactional analytic point of view, Goffman (1981) detailed social situations and the participation framework with regard to gatherings and encounters, ratified and unratified participants, overhearers and eavesdroppers. While ratified participants have the right to participate actively in the social encounter and the interaction, unratified participants do not, even if ratified participants might tolerate their presence and their listening.

Television viewers are generally considered as ratified participants, because television discourse is produced and designed for them (cf. Bell 1984; Dynel 2011). Spectators in videogames have only recently started to be the focus of research (cf. Lin/Sun 2011; Downs et al. 2014), mostly in the context of live streaming (cf. Kaytoue et al. 2012, Schmidt/Marx in this issue), where they are also considered as ratified participants (cf. Recktenwald 2017 drawing on Dynel 2014).

In our data, the situation is slightly different because players and non-players share the same physical environment and they alternate between playing and watching. Categorising participants as ratified or unratified does not allow for a fine understanding of how players and non-players interactively organise their social encounter, how they co-construct the participation framework (cf. Keating/Sunakawa 2011; Piraiinen-Marsh 2012), how they display engagement in the gaming interaction, whether they are players or not. Spectating is an "interactional matter, i.e., it is achieved moment-by-moment as a matter of participation with the current player" (Tekin/Reeves 2017: 10). The right to comment the game as a non-player and even to achieve the "status" of a co-player is constantly and locally negotiated by all participants (cf. Olbertz-Siitonen/Piirainen-Marsh/Siitonen in this issue). 
Spectating involves watching, a particular practice of seeing. From an interactional point of view, seeing has been described as "situated activity" (Goodwin/Goodwin 1996), "embedded in the activity one is engaged in" and "organised through the precise and fine coordination of the participants' conduct" (Nishizaka 2000: 121). Players might turn their gaze to different parts of the screen, but they only see what is "relevant to the development of the current activity and oriented to by the participants as a part of their activity in progress" (Nishizaka 2000: 113). If seeing in this sense is rather evident for players, since they are engaged in the activity of playing, it is not taken for granted for non-players ${ }^{1}$, who need to watch the game and the gaming activities. Watching can therefore be considered as a primary form of engagement and a way of constructing presence ${ }^{2}$. Tekin/Reeves (2017: 9) argued that “"seeing' done as a matter of spectating is not only about observing the movement of a player's feet". In other words, by watching the game, non-players (spectators) see movements as movements in the game, see the avatars' actions as emerging actions in the ongoing game and see their co-participants as players or non-players/spectators. They thus construct themselves as spectators and display this specific orientation through their embodied actions.

In this paper, we will outline how non-players become spectators or even co-players. We will demonstrate how spectatorship is achieved through different forms of participation and how participants become spectators while simultaneously enacting social relationships.

\section{Methodology and corpus}

The data are part of the research project "Ludespace: Videogame spaces in France" 3 . It consists in authentic and natural videogame situations involving a different number of participants. Gaming is not elicited: participants play the game of their choosing whenever, however long, and with whomever they want.

The dataset contains 20 hours of videogaming in 8 different situations. In nearly all situations, the participants are partly players, partly non-players. We identified as non-players individuals who are not

1 From now on, we use "non-player" to refer in a general way to all non-playing individuals.

2 We consider presence as "presence-process", as "the fruit of constant work on the part of actors in order to participate in situations on various different modes" (Licoppe 2014: 98).

3 Funded by the French Research Association ANR, 2011-2014. 
(currently) playing a given game but who are physically present. We distinguish them from players, who are actively involved in the game, even if they temporarily stop playing (but eventually come back to the game). ${ }^{4}$

We analyse 3 different gaming situations chosen because of their different constellations. This choice is motivated by the claim that the constellation (e.g. the type of the game, the number of participants, the use of space, etc.) enables specific ways of spectating.

- Tomb Raider: Underworld (Eidos Interactive, 2008), on Wii (Nintendo, 2006): Tomb Raider is a single player action-adventure videogame developed by Crystal Dynamics. It is presented in third person perspective, where the player takes control of Lara Croft. The recorded session is 90 -minute long and involves one player. The player's wife is sitting beside him on the sofa.

- Dance Central (MTV Games, 2010), on Kinect (Microsoft, 2010) XBox 360 (Microsoft, 2005) $)^{5}$ : Dance Central is a dance videogame, developed by Harmonix and compatible with the Kinect sensor. It offers thirty songs and five playing modes. In our data, the participants play in the "Perfom It!" mode where one single player dances to routines in the game. They take turns in dancing, the three non-players are sitting on the sofa, watching the player dancing. The whole session lasts about $15 \mathrm{~min}$.

- Dragon Ball Z Budokai Tenkashi 3 (Atari, 2007), on PlayStation 2: Dragon Ball is a fighting game where the players embody avatars, chosen from 23 characters at the beginning of the game. The recorded session involves five participants. Two players are playing in "Dual" mode (one against the other) with split screen. During the 50 minute gaming session, the five participants take turns, with two participants playing while the other three remain present, sitting in front of the screen.

4 According to us, "non-current players" are still involved in the game since they might be able to come back. They therefore participate in a different way than non-players who have a priori less obligations to watch the game.

5 This video game device allows players to physically embody the controller to interact on the console. With this device, the player uses his body to animate and advance his avatar in the actions of the game. 
The following table summarises the gaming sessions with their specificities.

\begin{tabular}{|l|l|l|l|}
\hline Doing Being... & a couple & Friends & a supporter \\
\hline Excerpt $\mathbf{n}^{\circ}$ & 1 & 2 & 3 \\
\hline Game & $\begin{array}{l}\text { Tomb Raider: } \\
\text { Underworld }\end{array}$ & Dance Central & Dragon Ball Z \\
\hline Console & Wii & $\begin{array}{l}\text { Kinect X } \\
\text { Box 360 }\end{array}$ & Playstation 2 \\
\hline Participants & $\begin{array}{l}1 \text { player } \\
1 \text { spectator }\end{array}$ & $\begin{array}{l}\text { 3 player } \\
\text { spectators }\end{array}$ & $\begin{array}{l}\text { 2 players } \\
\text { individual }\end{array}$ \\
\hline Mode & individual & individual \\
\hline Screen & 1 & 1 & 2 \\
\hline
\end{tabular}

Table 1: The gaming sessions analysed with its particularities.

We used the methodology of multimodal conversation analysis (CA thereafter), which focuses on the organisation of interaction by drawing on ethno-methods, practices developed by the participants to mutually display their understanding of what they are doing (Sidnell/Stivers 2013).

Previous studies on videogames have shown the importance of fine-grained sequential and multimodal analyses of gaming activities and interaction with other participants in and outside the game (Reeves/Greiffenhagen/Laurier 2017). If the notions of presence and participation of players and their avatars have already been investigated from a CA perspective (Baldauf-Quilliatre/Colón de Carvajal 2015; 2019), non-players have been the focus of less research. Tekin/Reeves (2017), in addition to their analysis on different ways of being a spectator, highlighted that video game designers and developers take into account spectators' experience.

Through its methodology and reflection on transcription and transcribing, CA allows for the detailed description of the embodied actions of players and events in the game (including the avatars' movements) taking place simultaneously. We used the transcription

6 The individual mode signifies there is not a team game where several players play in the same team. 
conventions developed for French interactions ${ }^{7}$ by the ICAR research lab, as well as Mondada's (2018; 2019b) recent conventions for multimodality. We adapted them to our data and research questions by using video clips and screenshots to highlight movements and simultaneous actions (Schmitt 2016; Laurier 2019).

The data involves different levels of embodied activities: (1) the game events and the avatars' movements, including in-game information (scores, help, etc.), visible on the screen, (2) the controlling activities of the players (movements on the controller, body movements for the Kinect device) and (3) the embodied interaction between players and non-players (including verbal turns as well as embodied actions). The three dimensions follow different temporalities, but they are interrelated. Transcripts which integrate all this are rather complex and quickly become illegible. We therefore generally use thumbnail images for on-screen activities and Mondada's conventions for the interaction. However, when the participants' interaction is mostly silent, we simply use thumbnail images or graphic transcripts.

We propose two different types of data presentation, depending on the angle for analysis. In section 4 , we present the different configurations of the three gaming interactions in terms of non-players' (spectators') participation practices with a special focus on the way how spectating practices are related to the enactment of specific relationships. For this, we study a longer extract and analyse the way in which game development (including in-game actions and controlling actions), watching, commenting, gazing, body movements of players and non-players, and spatial environment are intertwined. In this section, we do not draw on a detailed sequential analysis, our data are therefore presented with graphic transcripts, video clips, and (simplified) transcripts of verbal interaction. The main purpose of this section is to show how non-players become spectators and simultaneously enact specific relationships. We will argue that the way they watch the players is not determined by, but related to the way they enact another relationship. Section 5 is a detailed sequential analysis of specific moments from the longer transcripts, in order to show the fine-tuned temporal organisation of the interaction. This section draws on a detailed multimodal transcription (Mondada 2018) with thumbnail images, highlighting different embodied spectating practices with regard to the local multimodal accomplishment of participation.

7 ICOR conventions: http://icar.cnrs.fr/projets/corinte/documents/2013_Conv_ ICOR_250313.pdf 


\section{Ways of spectating}

In this section we illustrate three ways of spectating, drawing on the practices used by non-players to engage in the gaming activities and the way they simultaneously enact three different social relationships: doing being a couple, doing being a group of friends, doing being a supporter. We will show that the way non-players become spectators is related to the way they categorise themselves in this interaction. This relation is therefore not a simple one-to-one relationship (in the sense of doing being a couple always implies this particular way of spectating), but a complex intertwining of a) a specific configuration which enables particular practices, b) a specific categorisation with regard to the other participants and c) a specific way of spectating. Focusing on this relationship allows to better understand particular embodied practices (as described in section 5) with regard to the gaming situation and the social encounter which is constructed by all participants.

\subsection{Doing being a couple}

Our first extract shows a situation where one person (Greg) plays Tomb Raider: Underworld, on a Wii-console for the first time (Fig. 1). The extract comes from the very beginning of the game: Greg sits on the sofa and starts playing, while his wife Lucie sits beside him, doing something else on a tablet. The videoclip I ${ }^{8}$ (for extract 1 ) lasts 01:04.

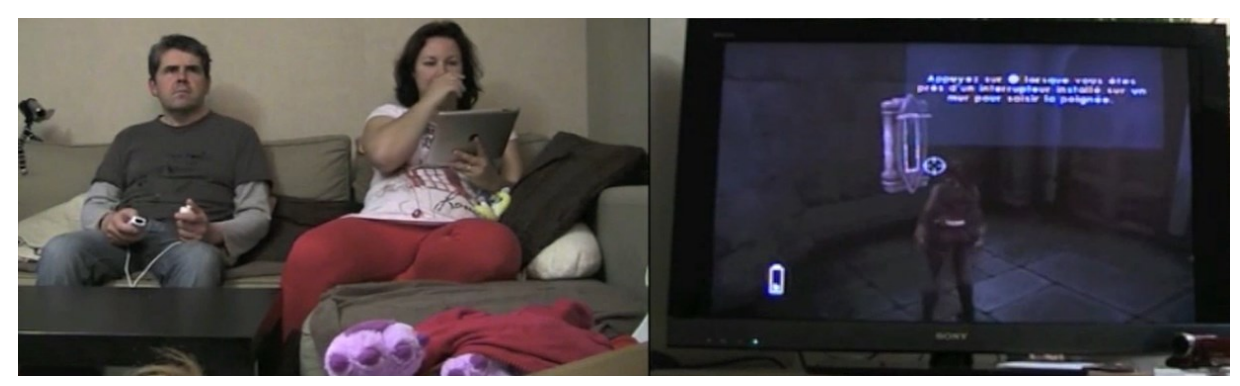

Figure 1: Tomb Raider game session on Wii.

Greg's avatar is placed in front of the door. Greg and Lucie are copresent, each occupied with a different activity. The spatial configuration allows both of them to stay informed about the other's activities and their development while following their own activity. No one else is present in the room. At the beginning of the extract, Lucie

8 We recommend watching the clips before continuing to read for a better understanding of the analysis. 
alternatively focuses on her tablet $\left(\mathrm{I} / 00: 12,00: 19,00: 33,00: 45^{\circ}\right)$ and Greg's screen (I/ 00:09, 00:18, 00:28, 00:38, 00:47).

She fluently engages in and disengages from the gaming interaction through her gaze, briefly and loudly reading an instruction appearing on the screen (I/ 00:33, 00:38, 00:45). After several unsuccessful attempts by Greg to advance further in the game (and to open a door), Lucie maintains her engagement in the gaming interaction and delivers several suggestions and corrective instructions (I/ 00:58 to $01: 04$ ).

What we see here can be described making reference to Schegloff/Sacks' (1973) "continuing state of incipient talk"10 or Goffman' (1981) "open state of talk" to lapses. Lapses can be treated by participants as a relevant cessation of talk, an allowable development of silence and a conspicuous absence of talk (cf. Hoey 2020). While Hoey's analyses mainly concern the local understanding of lapses in an ongoing interaction, in this section we focus on a larger perspective, considering the whole interaction or at least, longer sequences of activities. The extract shows how Lucie engages in and out of Greg's gaming, how the engagement develops from short gazes (lasting less than 3 seconds, I/ 00:09, 00:18), to rather short verbal monitoring (I/ 00:33, 00:38, 00:45), developed multimodal proposals, complex questionanswer sequences (I/ 00:58), and then back to silence and disengagement. At the beginning of the extract, Lucie's constant changes in gaze direction make her seem available and accountable for her co-participant Greg. Previous research on seeing as social accomplishment has mostly highlighted the co-construction of particular elements of seeing (what? where? how? who? etc.), here we are interested in Lucie's gaze and verbal turns as display of engagement in Greg's activity. The extract illustrates a non-player's shift of attention and therefore, her oscillating engagement as a spectator. It also orients to the embodiment of engagement practices in interaction: Lucie's suggestions are preceded by several moments of silent forms of engagement in Greg's gaming.

9 Moments in video clips are referenced by the number of the clip (roman figure), followed by the exact time code.

10 "Persons in such a continuing state of incipient talk need not begin new segments of conversation with exchanges of greetings, and need not close segments with closing sections and terminal exchanges." (Schegloff/Sacks 1973: 325). Incipient talk occurs for instance among "members of a household in their living room, employees who share an office, passengers together in an automobile, etc." (Schegloff/Sacks 1973: 324-325).

11 "[P]articipants having the right but not the obligation to initiate a little flurry of talk, then relapse back into silence, all this with no apparent ritual marking" (Goffman 1981: 134-135). 
If silences highlight the optionality of talk in certain situations, they have also been shown to be part of an ethnomethodological coconstruction of specific relationships. Skatvedt (2017) for instance describes co-silence as "one way for professionals to declare that the other is a subject in alignment with themselves. It is also a way of 'doing being human together'." (2017: 402). Stempfhuber (2013) claims with regard to couple interviews that the "silent social" is created by "performing intimacy in the gaps of language" (2013: 337).

Through their constant alternation between talk and silence without any particular signs of re-opening or closing the interaction, Lucie and Greg also orient to their relationship as "on-going accomplishment" (Garfinkel 1967). In this particular situation (two participants, sitting together on the sofa, each occupied by another activity and Lucie nevertheless monitoring Greg's gaming actions), they use this alternation to construct their relationship as "doing being a couple" (Isep 2014). We do not claim that all couples act in this way nor do we suggest that a continuing state of incipient talk is only used for "doing being a couple". Also, other categorisations are made relevant locally. However, Lucie's way of spectating in this extract (which is characteristic for the whole gaming session) contributes to the construction of an identity-in-talk and a special relationship.

\subsection{Doing being friends}

The situation is different in excerpt 2, where four friends are playing different games. Our example comes from the music rhythm game Dance Central using the Kinect motion peripheral (Fig. 2). The game consists in imitating the dance movements of an avatar. Thus, the shared activity is watching the performance of the player.

As in the previous section we do not want to say that the way of spectating we describe here is only used by friends, it rather contributes to a categorisation as friends in this particular setting.

In the excerpt, Dom has just finished his performance. He reconfigures the song for Lucas, who is about to start, and sits down on the sofa. Vero and Lea are already on the sofa, waiting for Lucas to start. Lucas is standing between the spectators and the screen. So he can see the screen but not his friends, while they can easily see him and the screen. Videoclip II for extract 2 lasts 00:52. 


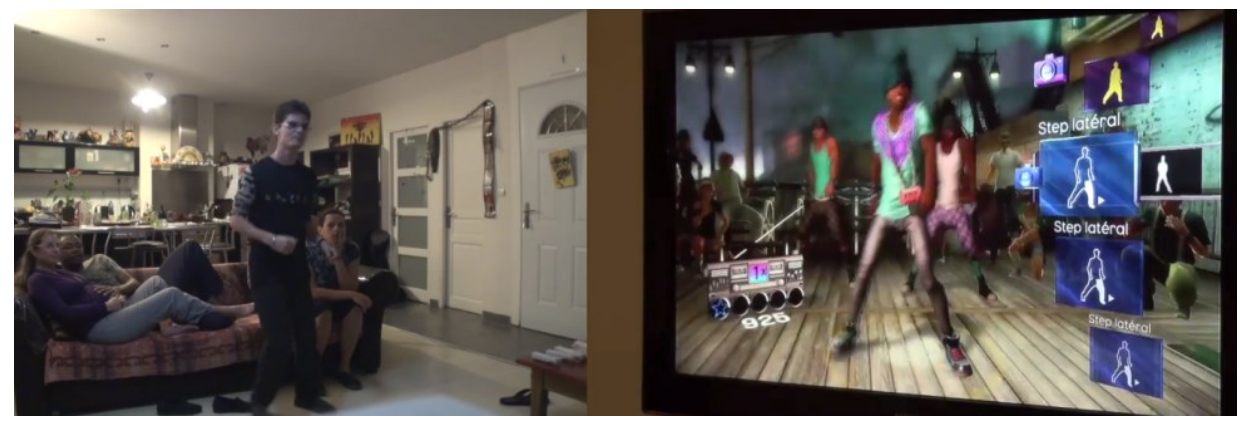

Figure 2: Dance Central game session on Kinect.

If Dom, Lea and Vero want to participate in the gaming interaction, they need to do it vocally since they are not in Lucas' visual field. Simultaneously, Dom, Lea and Vero can more easily display to each other whether they are participating in the gaming interaction. They also can form ephemeral groups by orienting their bodies to one another (cf. Baldauf-Quilliatre/Colón de Carvajal subm.).

In contrast to excerpt 1 , even though there are also periods of longer silences, the spectators do not constantly shift between engagement and disengagement from the spectating activity. During Lucas' entire performance, they maintain their focus on the player and his performance with different types of comments, demonstrations and instructions, gaze and body orientation. For example, Vero, who does not much participate vocally, displays her engagement through a rather fixed position, her upper body bent forwards, her gaze fixed on the screen (II/ 00:11).

The excerpt ends with a complex teasing sequence (II/ 00:37 to 00:51) where Lea und Vero form an ephemeral group by looking at/ turning their gaze to each other and creating rapport with laughter.

If the situation in excerpt 1 is characterised by a continuing state of incipient talk and by constantly alternating between the gaming interaction and a concurrent activity, excerpt 2 displays a continuous engagement in spectating. Dom, Lea and Vero watch Lucas' performance as they might watch a movie: their posture on the sofa/ couch is relaxed, looking at Lucas and the screen without staring at them. Watching a movie has been described as a particular type of interaction, concerning the accomplished actions as well as the organization of interaction (cf. Holly/Püschel/Bergmann 2001). Holly/ Baldauf (2001) characterised it as empractic (i.e. embedded in other activities), observing and receptive. This means that participants interact with regard to the principal activity and depending on it. Their actions organise, appropriate, interpret, categorise and evaluate what they see, they assure comprehension or display amusement (cf. Klemm 2000) and therefore contribute to the social organisation of the group. 
A similar observation was made by Reynolds (2017) for training sessions where teammates watch powerlifting exercises. He showed that watching the lift and encouraging the lifter is not only used to create a particular relationship between the two participants directly involved in the interaction, but also orients "to a collective shared experience, with an emphasis on the collectivity of this experienced moment" (Reynolds 2017: 114).

In a similar way to "teammates" in Reynold's data, Vero, Dom and Lea watch Lucas' performance and comment on what he is doing. Consequently, they establish a joint orientation (cf. de Stefani 2014) to particular aspects and orient to a shared experience including all four of them from a different participant status. By doing so, they categorise themselves as being part of a group of friends.

\subsection{Doing being a supporter}

Excerpt 3 illustrates a third type of configuration. Five friends are sitting around a coffee table and playing different types of games, including the fighting game Dragon Ball $Z$ where two players fight each other through avatars of their choosing (Fig. 3). In this extract, Rod and Max are playing, the three others are non-players (spectators), watching them. Max and Ben are sitting side by side on the sofa, Cel is sitting in the armchair and Rod on a chair, all four around the coffee table, able to focus on the screen as well as on each other. By contrast, Xav is sitting on the floor, in front of the screen, with his back to Rod and Cel. He can easily be seen by his friends but he cannot see Rod and Cel, and has even difficulties seeing Max and Ben.

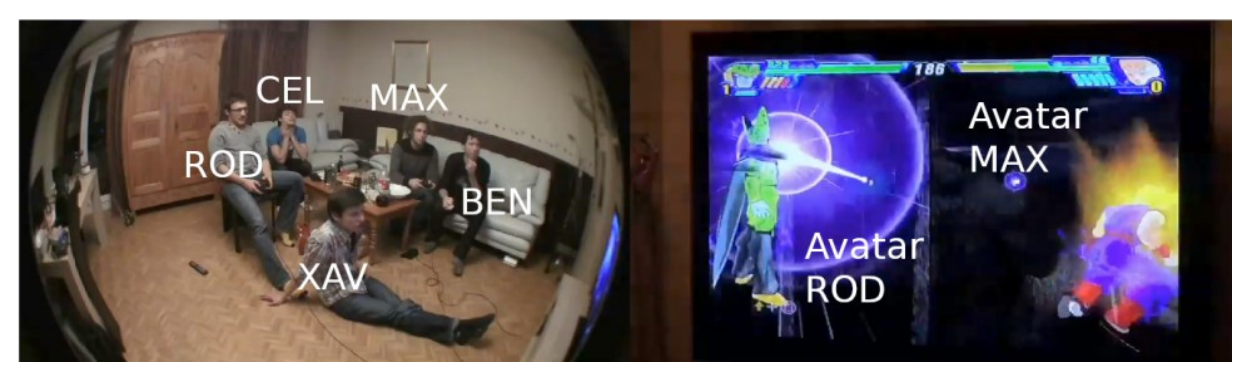

Figure 3: Dragon Ball Z game session on Playstation.

Throughout the fight, the 4 friends comment, assess, encourage and instruct the players nearly constantly. Lapses, such as those found in excerpt 1 or even excerpt 2 , are not frequent. The excerpt starts with several sequences where Xav instructs and encourages Rod.

Xav cannot see how Rod manipulates the console (Fig. 3) but deduces it from the actions and movements on the screen. When Rod wins a fight due to Xav's instructions, Xav turns around and initiates 
a sequence with Cel about his role as a "coach" (III/ 00:14). He then faces the screen again and announces his "support" of Max from now on, as Max is underdog now (III/ 00:20). Several sequences of instructions follow.

While the spectators in extract 2 were watching a movie (in the sense of "watching and commenting the gamer's performance"), in extract 3, Ben, Xav and Cel are watching a match between two parties and they support one of them. Whom they support is negotiable and depends on the situation; the spectators can transfer their support whenever they judge that it warranted by a new development. Similarly to Gerhardt's (2006) description of "watching football on television", watching a competitive videogame can be described as community of practice (Wenger 1998) where particular ways of doing things emerge. Videogame spectators show their expertise, by displaying precise knowledge, independently from what they actually see on the screen. For example, Xav deduces from the avatar's movements how Rod uses the controller and asks him to accomplish other, more efficient actions indicating which buttons or combinations of buttons to press (III/ 00:02 to 00:06, 00:08). He positions himself explicitly as a "coach" who holds the knowledge and the rights to instruct and assess Rod. At the same time, the spectators "picture themselves on the terraces" (Gerhardt 2006: 137) in a similar way to Gerhardt's football spectators. Xav and Cel display their support (e.g. by instructing, assessing or encouraging), show engagement and emotional involvement (e.g. by their body orientation to the screen) and even discuss their supporting in front of the players, Rod and Max (III/ 00:12 to 00:22).

The spectators' interaction in this excerpt can partly be described as "doing being a supporter". Xav is not only watching and commenting a movie, he defines himself as "coach" and "supporter" and therefore orients to another type of watching. His participant status is validated by the players who comply with his instructions. Even if Cel and Ben do not join Xav's supporting position in this excerpt, they act similarly at other times during the match (e.g. the excerpts discussed in Baldauf-Quilliatre/Colón de Carvajal 2019; 2020) and they show their engagement in the gaming activity with their continuing body orientation to the screen (Fig. 3).

\subsection{Discussion}

The three extracts show three different configurations of game type/genre, spatial configuration and engagement of non-players as spectators. The various participation practices depend in part on the configurations and the affordances of the game, and in part on how the affordances construct the configurations. 
While a slow problem-solving approach is possible in a firstperson adventure game such as Tomb Raider, fast decision-making is necessary in a fighting game such as Dragon Ball Z, which precludes longer discussions and explanations. A single-player game allows for the observation of one participant's actions, when a multiplayer game makes it possible to support different teams. Engagement can be enacted through different modalities in situations where non-players and players can see each other. However, when this is not the case, engagement needs to be expressed verbally and/ or vocally. Different non-players can interact as spectators or might even form ephemeral groups, but for a single non-player, the only possible interaction is with the player(s). Additionally, engagement in other parallel activities means that orientation and engagement are distributed between activities, while more involvement as a spectator could be expected of non-players who are not otherwise occupied.

On the other hand, with their constant focus on the gaming activities, displayed through body posture, gaze and verbal turns, nonplayers position themselves as spectators or co-players (cf. OlbertzSiitonen/Piirainen-Marsh/Siitonen in this issue). The accumulation of directives and encouragement sequences, as well as the fastpaced nature of the game, leads to an outwardly emotive way of spectating, as the players become excited. This is in contrast with a slower-paced tempo with suggestions or (longer) explanations. The negotiation of epistemic stance and status also contributes to configure the participation framework. By displaying an epistemic stance and claiming the rights to display it (as with technical directives about controller use), non-players also claim the rights to participate in the gaming activity. In contrast, the rather late appearance of a verbal turn, (e.g. a suggestion given after several unsuccessful attempts) or a visible doubt shown in the turn design can indicate a lower claim on epistemic authority and a different positioning of the spectator.

In the three extracts analysed so far, non-players do different things and categorise themselves differently, and yet, they all watch the game. Lucie's and Greg's interaction in extract 1 can be described as way of "doing being a couple". The interaction of the three spectators and player Lucas in extract 2 can be understood as "doing being a group of friends". The three spectators in extract 3 act as supporters and the interaction between spectators and players in this extract can be categorized as "doing being a supporter". 


\section{Embodied practices of spectators' participation}

In this section, we focus on the local co-construction of non-players' (spectators') embodied practices to show engagement and the interaction between spectators and players. We present a detailed sequential and multimodal analysis of several moments of the three extracts, which highlights the fine-tuned temporal and multimodal construction of non-players' engaging in the gaming activities and their displays of participation. Since the different ways of spectating reveal different practices, we divide this section into three parts which correspond to the three larger extracts.

\subsection{Co-construction of alternating engagement (Extract 1)}

With the first extract, we focus on the co-construction of nonplayer's engagement as spectator and the way player and non-player interactively construct their shifts of attention from two individuals each focused on their own activity, to an interaction between player and co-player.

The extract starts with a rather long silence $(33 \mathrm{sec}$.) where different non-vocal actions succeed one another (see 4.1). During these 33 seconds of silent play, Lucie observes Greg's unsuccessful actions and makes her seeing accountable by the constant changes of gaze direction as well as by the different duration of gazing. Greg keeps making the same movements but fails to reach the desired outcome in the game (open the right door). When he raises his arms again, producing a vocalisation for the first time, this could be understood as a trouble alert (cf. Kendrick/Drew 2016). However, Lucie does not offer assistance. However, she responds to the trouble alert by "so what" and hereby gives Greg the opportunity to for instance ask for help. Then, she turns back to her tablet and displays monitoring. Trouble alerts "do not establish a normative obligation on Other(s) to provide assistance" (Kendrick/Drew 2016: 8), but they "solicit the attention" (Kendrick/Drew 2016). In other words, Greg indicates a potential trouble alert and Lucie displays her understanding but does not offer help (I/ 00:36 to 00:41 "raise the Wii's remote controller").

Until then, Lucie has focused alternatively on her tablet and the gaming screen. Her glances back and forth make it possible for her to follow on-screen events, assess Greg's movements (as well as their tempo) and display monitoring without observing the player constantly. Meanwhile, Greg focuses on the screen and behaves as an individual player without explicitly responding to Lucie's glances or verbal turns. Nevertheless, he makes his trouble visible (thanks to trouble alerts and embodied displays of trouble such as repeated 
movements) and creates an opportunity for her to assist him and take part in the gaming activity.

After having read the on-screen instructions, Lucie shifts her focus of attention back to her tablet, leaving Greg to continue his attempts (I/ 00:43 to 00:46). However, she does not focus on the tablet for long $(2.5 \mathrm{sec}$.) and soon orients again to Greg's gaming. She monitors his unsuccessful actions by opening a teasing sequence (I/ 00:45 “it'll frustrate/upset you I guess ((laugh))"), turning her gaze from the tablet to the screen during the turn. Gaze shifting within the turn has been analysed as providing evidence for the fact that "participants frequently attend to multiple visual fields simultaneously" (Goodwin 2007: 56). In this case, Lucie's gaze shift also clearly displays her availability for assistance.

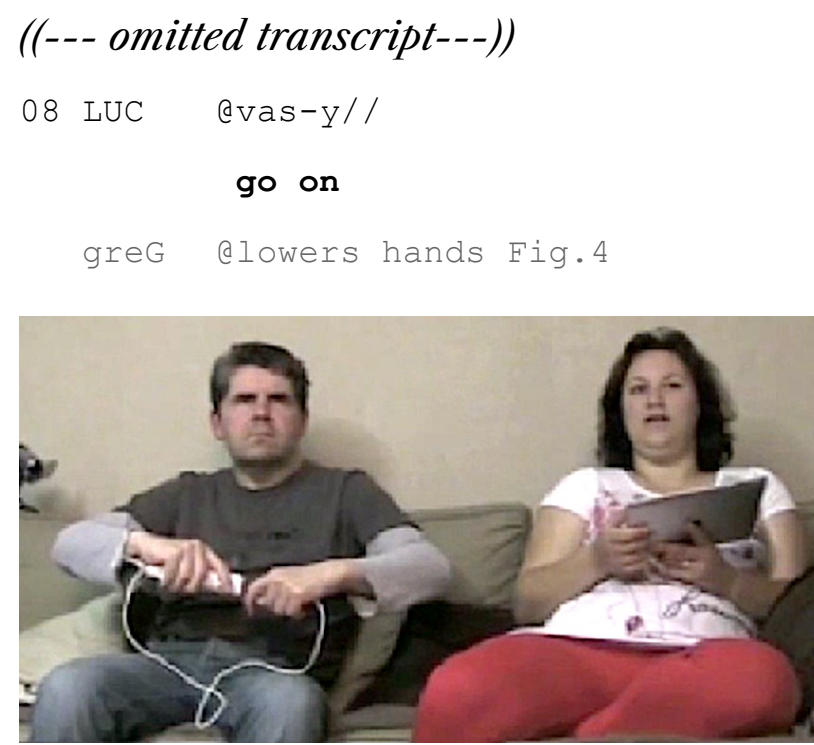

\section{Figure 4}

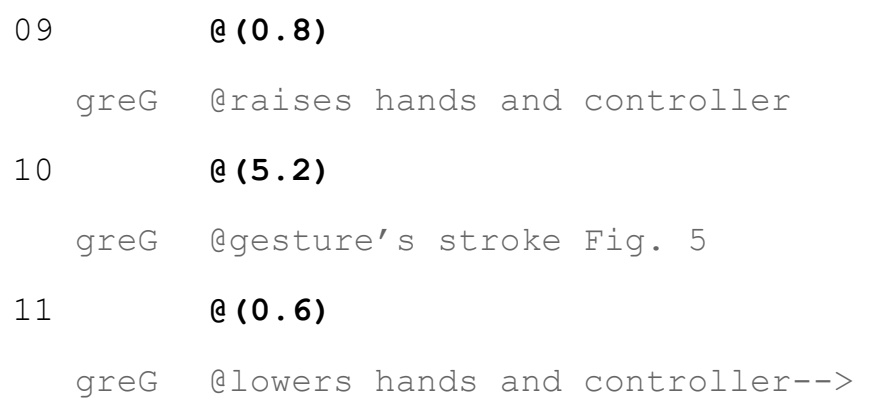




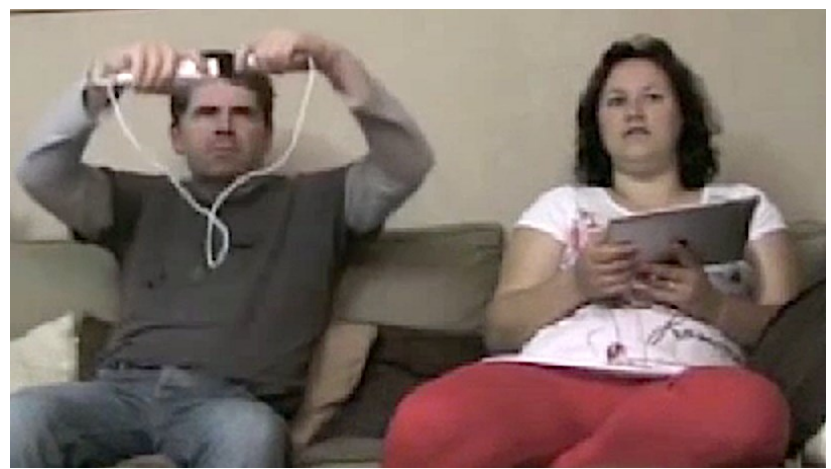

\section{Figure 5}

12 LUC *rapide $@ j ’$ pense

quick I think

lucG * quickly lowers her right hand Fig. 6*

greG --> Qhands on knee-->

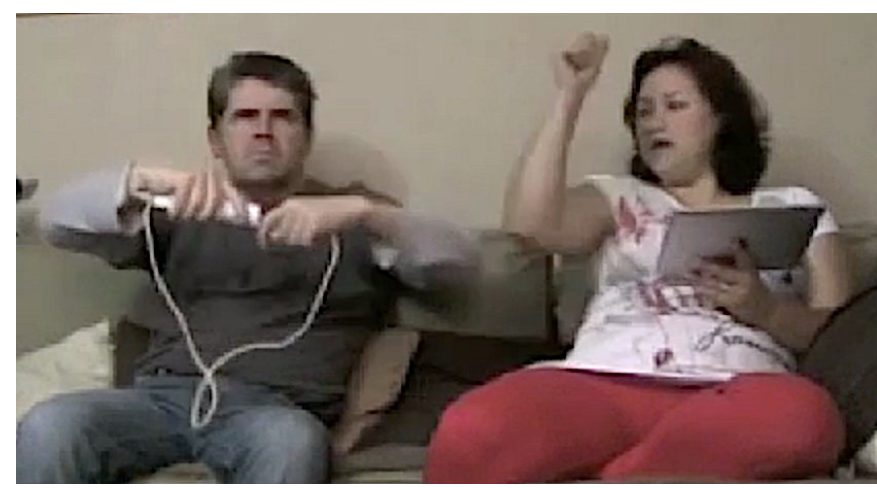

\section{Figure 6}

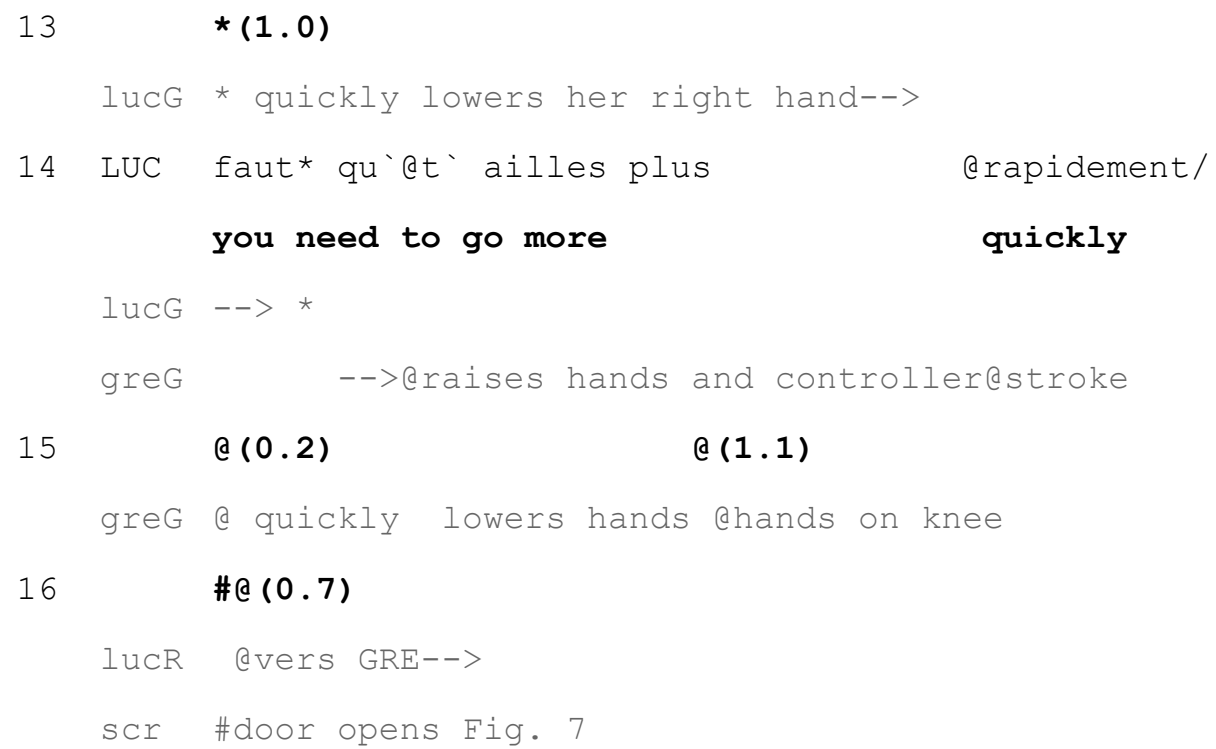




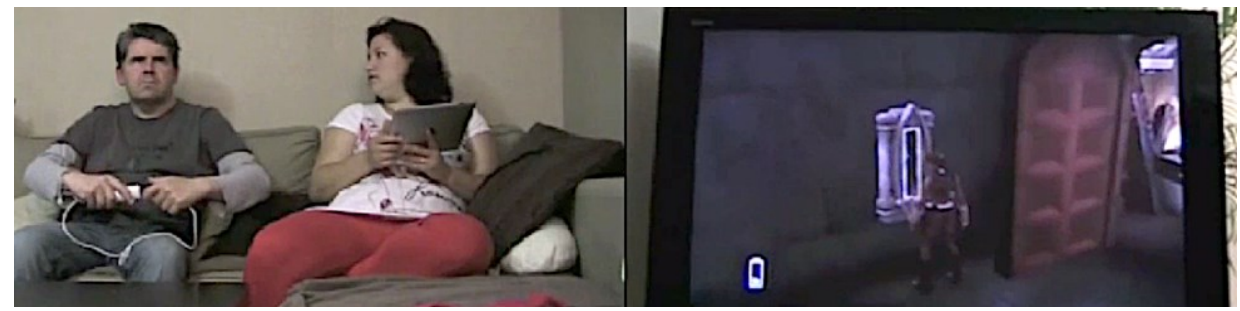

\section{Figure 7}

From this point, Lucie's gaze is focused on the screen for the next 17.8 seconds. While Greg keeps moving, Lucie produces a second turn which is interpreted by Greg as encouragement to continue (Baldauf-Quilliatre/Colón de Carvajal 2020): He keeps on doing the same movements in the same slow way (1.8-11, Fig. 4 and Fig. 5).

Lucie then corrects Greg's movement by formulating a corrective instruction which she enacts by accomplishing a rapid arm movement (1.12-13, Fig. 6, I/ 00:59)). In the following turn, she insists on the correction by rephrasing it in a more explicit way (1.14). Greg complies and the door opens (1.14-16, Fig. 7, see also I/ 01:02 to 01:04).

Once the problem is solved, Lucie and Greg continue their discussion "out of the game" before turning back to their respective activities (not shown in the transcript).

The detailed analysis of the extract provides evidence for the coconstruction of spectating. Initially, Lucie follows Greg's gaming activities (by glancing up and down from her tablet to the screen) without showing engagement as co-player. Greg for his part acts on his own, disengaging thereby from interaction, focusing on the screen. Gradually, Lucie displays her availability for interaction with longer gazing and vocal turns, while Greg makes his trouble visible through trouble alerts and embodied displays of trouble. When Lucie shows higher engagement in the interaction, shifts into a participation framework as co-player and opens a corrective instruction sequence, Greg also engages in the interaction with Lucie as coplayer by complying with her suggestion, even though his gaze remains focused on the screen. In the last part of the extract (not shown), both participants are similarly engaged in interaction. They are no longer involved in their individual activities but interact without accomplishing other activities simultaneously and look at each other. At the end of the extract, Greg focuses again on the screen and continues playing while Lucie turns back to her tablet. By shifting their gazes away from each other, they both display their changes in participation framework and their momentary disengagement from interaction. 


\subsection{Co-construction of ephemeral groups (Extract 2)}

The analyses of the second extract focus on two aspects: (a) the nonplayers' co-construction of specific forms of engagement; (b) the coconstruction of ephemeral groups.

While we have shown in the previous section how players and non-players co-construct engagement and disengagement in the gaming activity, this extract shows how the non-players and the player co-construct particular forms of engagement in a situation where the engagement of the non-players as spectators/co-players seems to be established already.

At the beginning of the extract, Lucas starts dancing and Dom and Lea analyse in situ the dancing movements which have to be produced in real time, synchronised with the avatar on the screen. They initiate four instruction-sequences $(1.18,20,23,27)$, produced in particular positions with regard to Lucas' temporal alignment with the on-screen avatar.
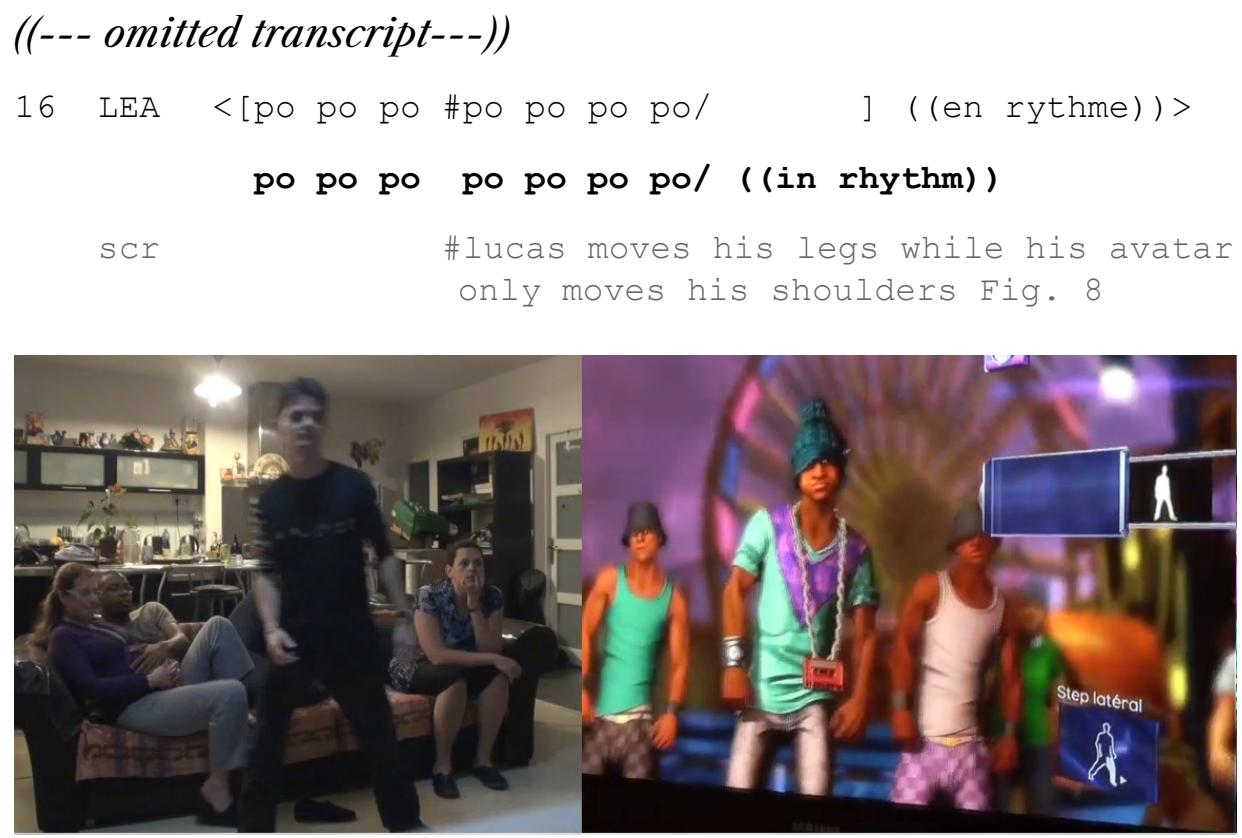

\section{Figure 8}

$\begin{array}{lll}17 & & \text { (0.5) } \\ 18 & \text { DOM } & \text { atten:ds/ } \\ & & \text { wait/ } \\ 19 & & \mathbf{( 0 . 5 )} \\ 20 & \text { DOM } & \text { maintenant/ } \\ & & \text { now/ }\end{array}$



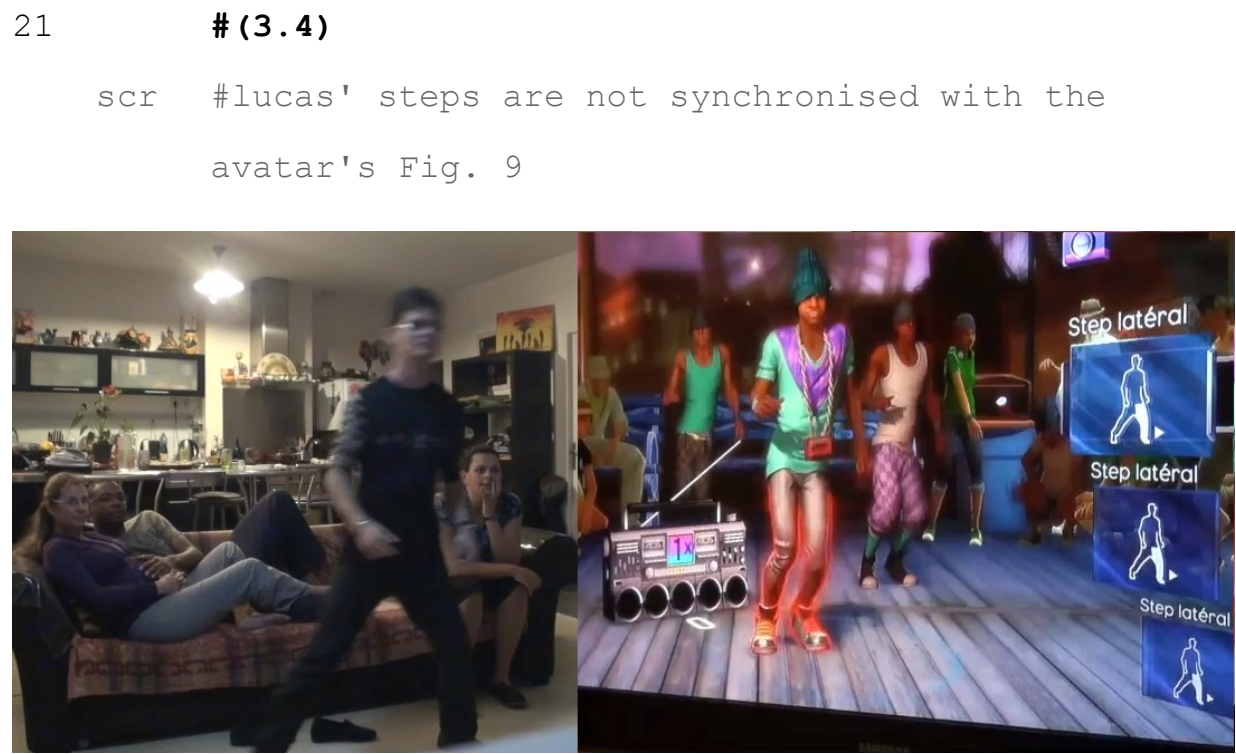

\section{Figure 9}

22 LEA \#droite/ (0.6) gauche \yes: : $(0.5)$

right/ $(0.6)$ left $\backslash$ yes: : \(0.5)

scr \#lucas synchronises with his avatar at the end of lea's turn Fig. 10

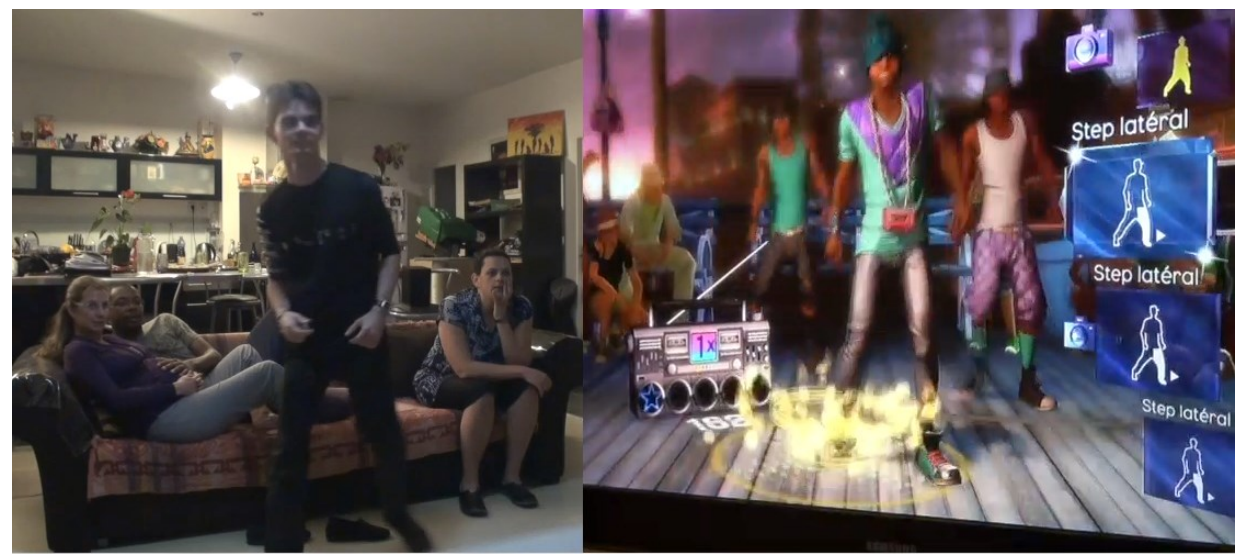

\section{Figure 10}

23 LEA \#Ça y est c'est parti/

that's it let's go/

scr \#lucas is synchronised with his avatar Fig. 11 


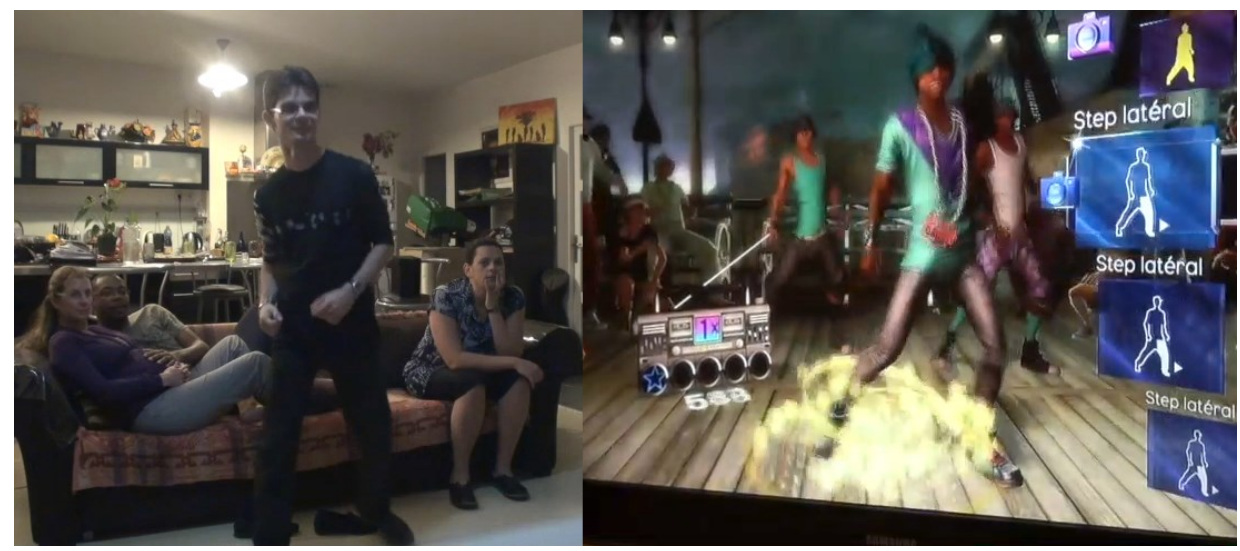

Figure 11

$24 \quad \#(2.8)$

scr \#lucas becomes unsynchronised again Fig. 12

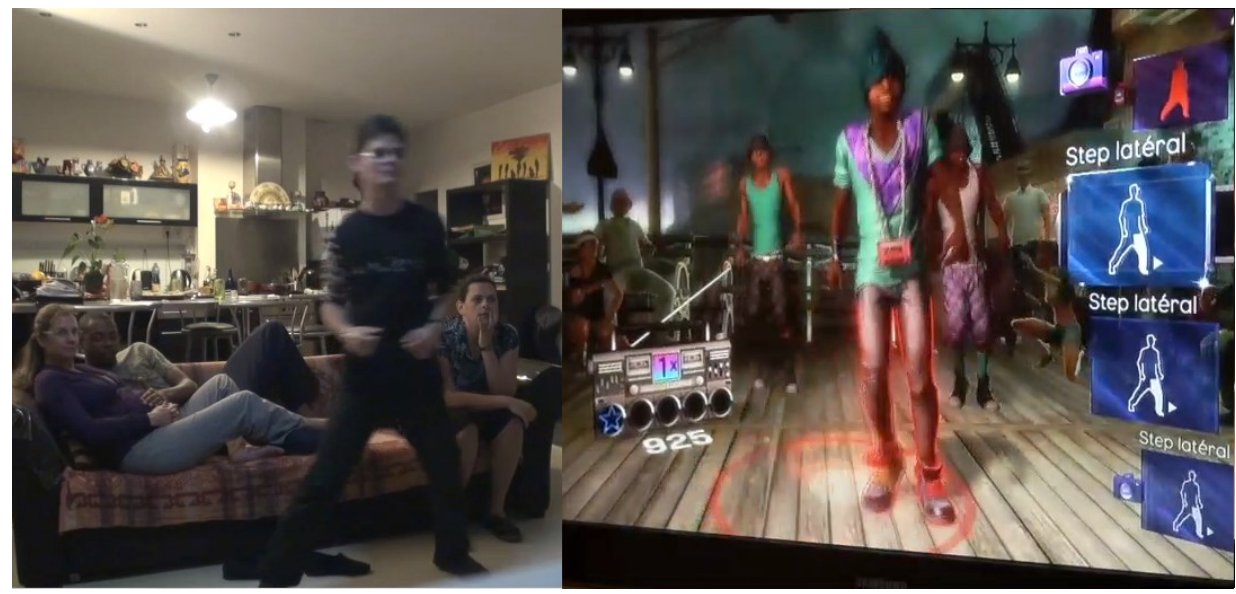

Figure 12

25 LEA pas trop vite//

not too fast

None of the different instruction sequences was requested by Lucas. By offering the instructions, Dom and Lea display that they are watching the game, which means that they are watching Lucas and the avatar on screen. Lucas accepts the instructions as such by displaying an attempt to accomplish the instructed action (waiting, starting again) or to correct it (following the rhythm and going in the correct direction). By instructing Lucas, Lea and Dom also display expertise, indicating that they know (better than Lucas) what to do, that is, how to move and therefore how to play. This means that they position themselves not only as ratified participants having the right to watch, to instruct, but also as fully ratified participants having the right to contribute to the progression of interaction, to reveal their knowledge (cf. Heritage 2012; 2013). Simultaneously, they frame the 
player as somebody who requires assistance, a position which is tacitly accepted by Lucas himself.

Shortly after this extract starts a jocular teasing sequence (cf. Günthner 1996; Haugh 2016) where the three non-players laugh at Lucas who is still struggling with synchronization. The sequence starts with Lea initiating a smile in line 36 , then collectively, they burst into laughter. The laughing follows the worsening asynchronisation between Lucas' and his avatar's movements (II/ 00:25 to 00:37). Lucas starts clapping his hands asynchronously with the ava$\operatorname{tar}$ (red lines on the avatar's arm and fixed score on 925; Fig. 13).
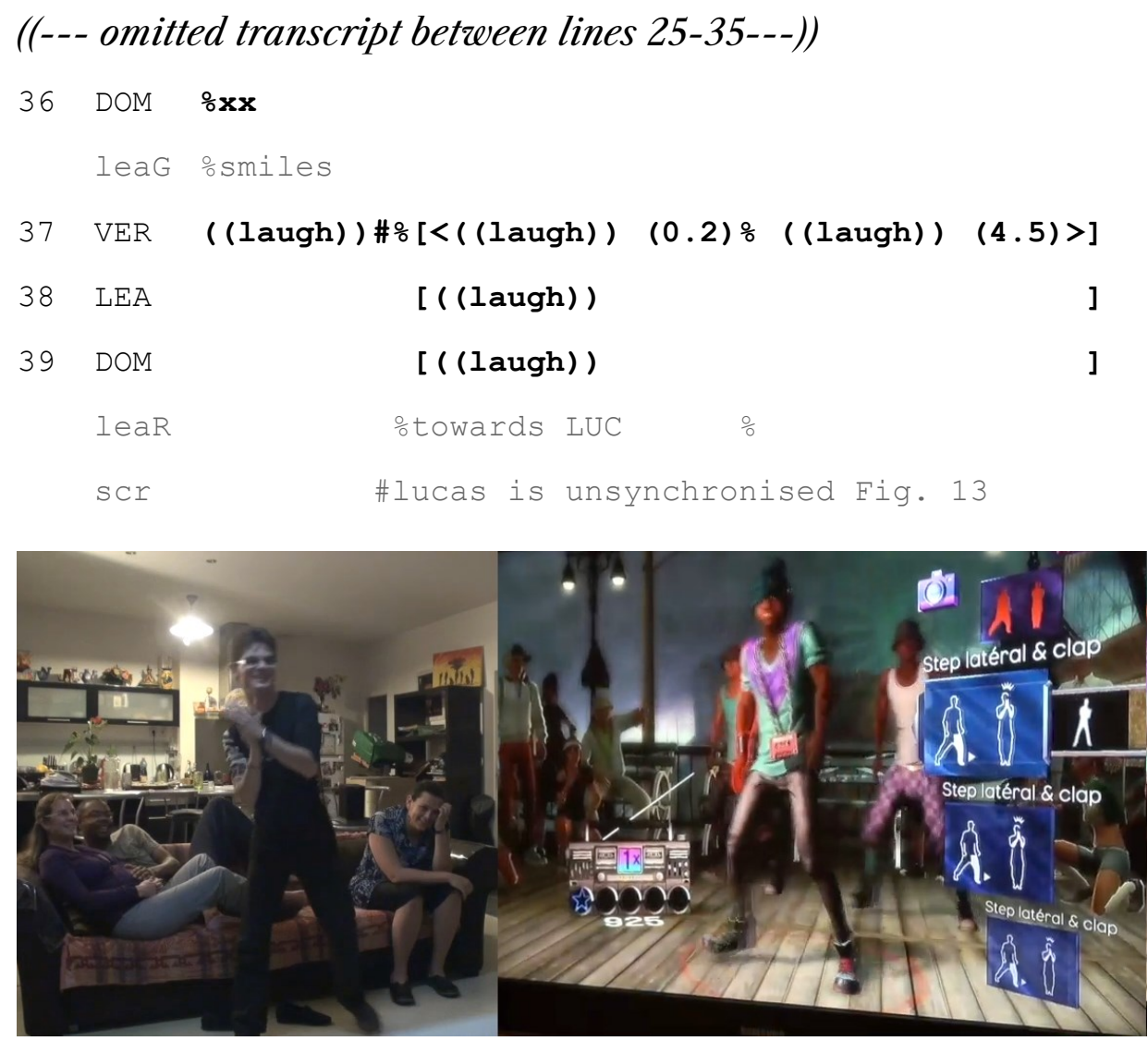

Figure 13

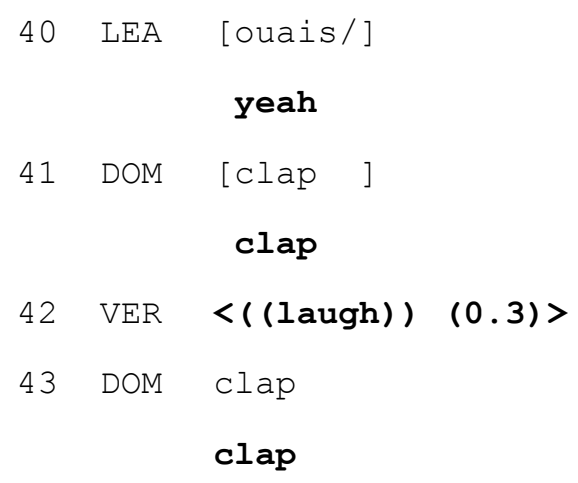




$$
\begin{aligned}
& 44 \text { LEA \#[(( augh) })]<((\text { laugh })) \quad(0.7)>[((\text { laugh }))] \\
& 45 \text { DOM [clap ] [clap ] } \\
& \text { clap clap } \\
& \text { scr \#lucas is still unsynchronised Fig. } 14
\end{aligned}
$$

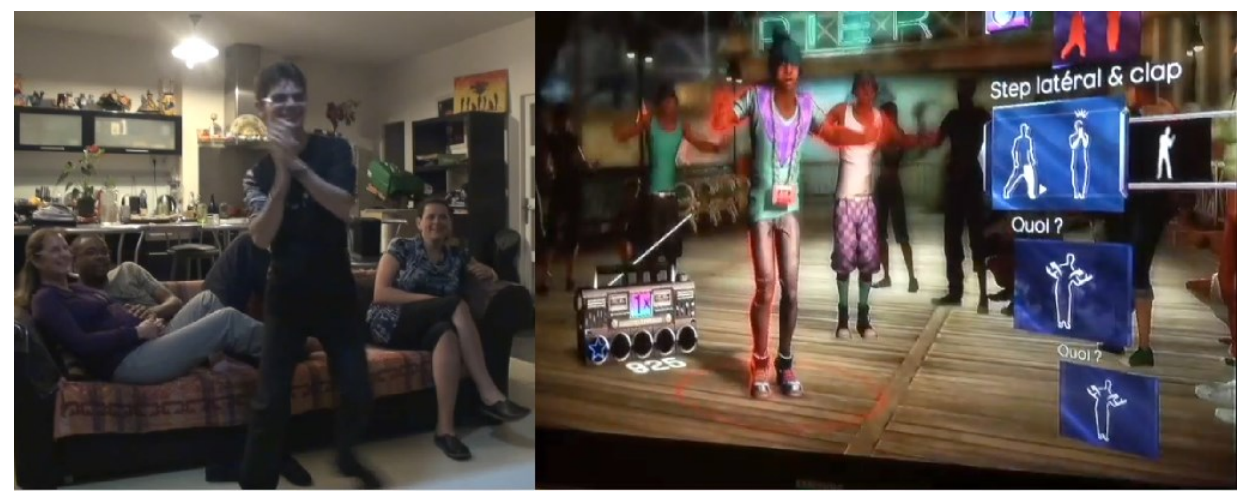

\section{Figure 14}
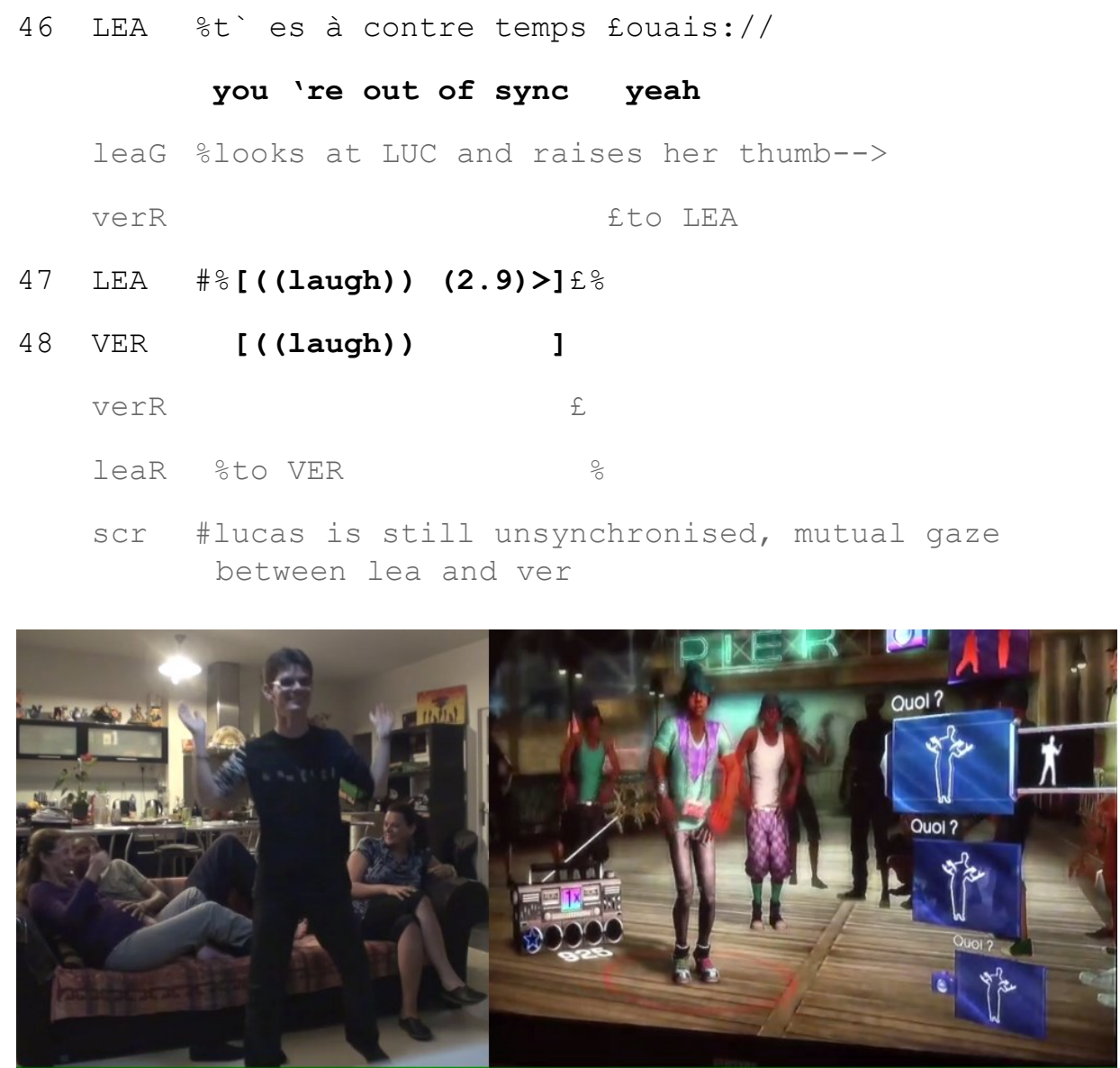

\section{Figure 15}

\section{DOM (go on)}


50 $\#(0.8)$

$\mathrm{SCr}$ \#lucas is synchronised with his avatar Fig. 16

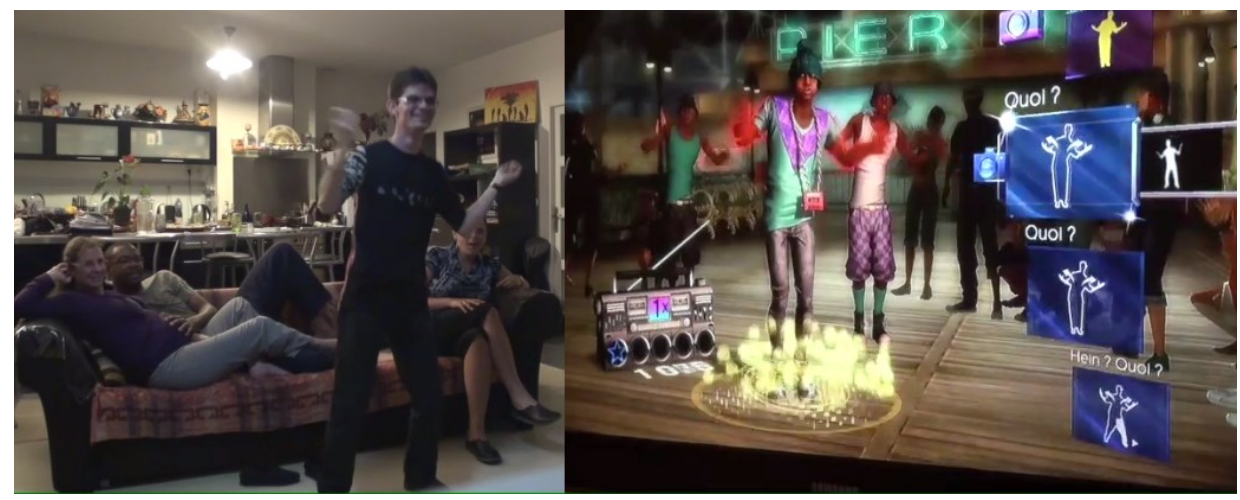

Figure 16

51 LEA yeah: \

yeah

While the three non-players engage in shared laughter for a while (1.37-48), they do not coordinate their laughing with mutual gaze. Nevertheless, the collective laughter displays a joined positioning with regard to Lucas' performance: The three non-players act as a group distinct from the player who is framed as the subject of mockery. Christmann (cf. 1996: 62-63) has argued that early shared laughter in mockery sequences is due to shared knowledge and shared basic convictions. When Dom, Lea and Vero burst into laughter together rather early during Lucas' performance, they claim a nonserious intent (cf. Haugh 2016) and mutually display their shared positions and knowledge about Lucas' dancing. Thus, they create an ephemeral group, excluding Lucas.

Simultaneously, Dom opens an instruction sequence involving Lucas and himself $(1.41,43,45)$. He verbalises Lucas' action (“clap", $1.41,43,45)$ in sync with Lucas' avatar. In this way, he indicates the action to be done by Lucas, but also the precise moment when it needs to be accomplished. In spite of Dom's indications, Lucas' hand clapping remains asynchronous (red lines on the avatar's arms and legs and fixed score (Fig. 14, II/ 00:42 to 00:46). Dom is thus involved in two sequences: verbally and through gesture in the instruction sequence with Lucas, and by facial expressions (he continues smiling after the outburst of laughter) in the teasing sequence with Lea and Vero.

Line 46, Lea initiates another sequence, explicitly addressed to Lucas. She constructs her turn as a positive assessment, accompanied by a hand gesture (raised thumb), looking at Lucas (Fig. 15). In contrast to Haugh's (2016: 129) findings that "in the case of jocular mockery a return to serious talk is positioned as properly due in next 
position", Lea does not return to serious talk, but continues teasing. Despite the explicit address, Lucas is still treated as an "object of amusement". Furthermore, during Lea's turn, Vero starts turning her gaze to Lea, and Lea looks back at Vero (Fig. 15). Both burst out into laughter. By laughing together and reciprocally orienting their gazes towards each other, Vero and Lea construct a moment of intimacy and of amusement (II/ 00:46 to 00:50).

Indeed, amusing has been described as one of the principal actions in which spectators are involved (cf. Klemm 2000). Television viewers as analysed by Klemm are "between their own four walls" and thus "unobserved" by the object of amusement (Klemm 2000: 189, our translation), which allows them to act differently than if they could be heard by their "object". ${ }^{12}$ In our data, Lucas cannot see the spectators, but he can hear them. Even if he is positioned as the "object" of amusement, he is present and can potentially respond to the mockery. In the extract, he does not produce an answering turn, but he continues playing and smiles. At the very least he does display rejection, but more probably signals his acceptance of the mockery (cf. Haugh 2014).

Nevertheless, laughing ends soon and line 51, Lea turns back to more serious talk by acknowledging Lucas' performance as correct ("yeah") after he has synchronised his movements with the avatar, indicated by the yellow lines and an increasing score (Fig. 16, II/ 00:50 to 00:52). Following Haugh (2016), this turn displays not only a return to more seriousness, but also a shift in the participation framework: the ephemeral group of spectators is disbanded.

The different overlapping sequences illustrate the dynamics of the participation framework. While the player is engaged in the gaming activity and in some sort of interaction with the avatar, the non-players interact with the player and thus construct their spectatorship interactively, but they may also interact among themselves, more or less excluding the player (not addressing him). In our extract for instance, Lucas also laughs silently, indicating somehow his participation in the jocular mocking, even if he is not addressed by Lea and Vero, and even when he is engaged in another activity. Nonplayers as well can interact simultaneously in different participation frameworks, with other spectators and with the player. In all these cases, players and non-players use different multimodal resources for displaying participation, as we discussed for Dom.

12 Though this does not mean that moral implications are suspended (cf. Klemm 2000: 190). 


\subsection{Coaching (Extract 3)}

While section 5.2 has shown how non-players can position themselves as active spectators and co-players, with this positioning validated by the player, this section focuses on a particular form of spectating, namely, coaching. Extract 3 is characterized by a specific gaming configuration: two players are present and playing against each other. In section 4.3 we showed that the game is watched like a football match - the non-players display their support for one of the players. In this section, we analyse in detail how this support is constructed interactively and what it means to coach a videogame player.

The excerpt begins with several instruction sequences. All three non-players are watching the game and display their engagement as spectators non-verbally. Xav and Cel show a particular engagement since they address verbal turns to one of the player, Rod. While Max' on-screen avatar is getting stronger and stronger (Fig. 17), in preparation of an attack against Rod's avatar, Xav produces a technical instruction addressed to player Rod - he should activate a particular button on the controller "with xxx down arrow" (1.2). Simultaneously, Cel produces an unintelligible turn which seems to be addressed to Rod as well (he touches Rod's arm during her turn, 1.3). Xav and Cel thus show their engagement in the game through different productions addressed to player Rod who is preparing his avatar for a particular in-game action, namely, the "super ray of death" (Fig. 18).
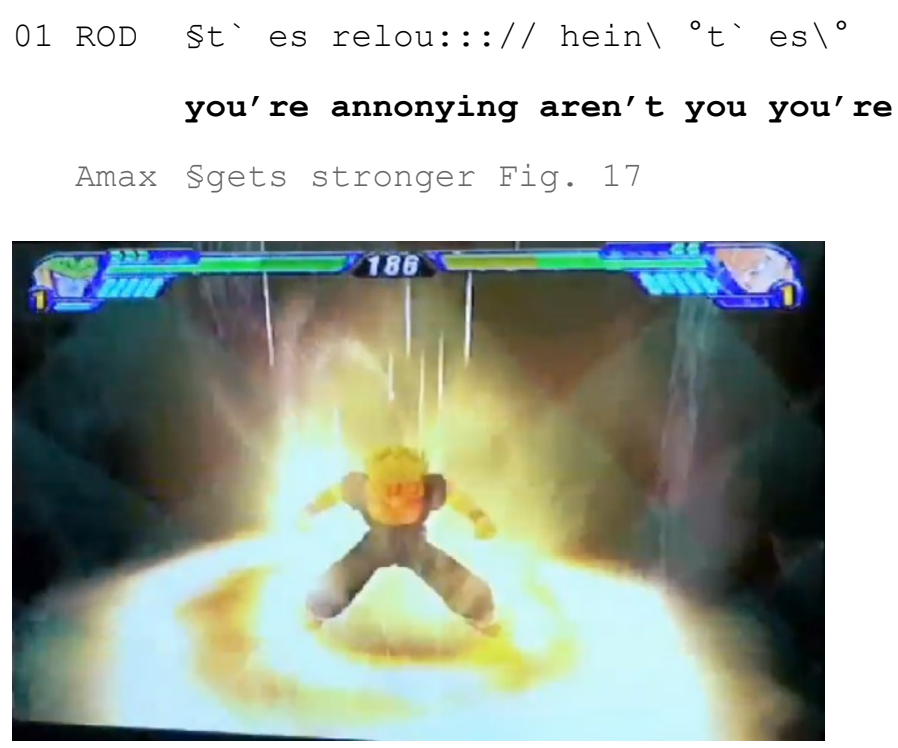

Figure 17
$02 \mathrm{XAV}$
\$잉 avec $x x x]$
flèche du bas $\backslash \$$
with $\mathbf{x x x}$
down arrow 

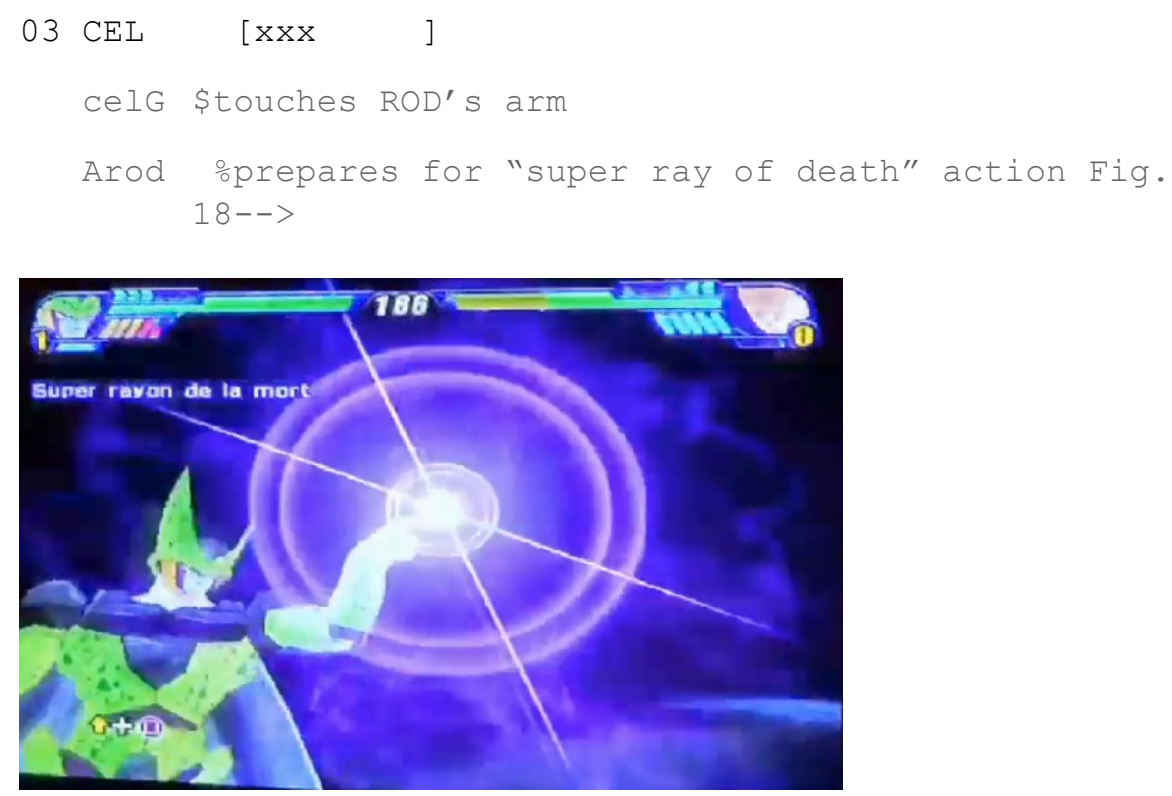

\section{Figure 18}

$04 \quad(0.4)$

05 XAV nan là/ tu flèches/ euh: \o normal là

nah here you (press) arrow uhm normal here

06 XAV C'est flèche du bas o $\$(2.0)$ éloigne toi vite//

it's down arrow (2.0) get away quickly

Arod ogets stronger Fig. 19a

Amax Sprepares for "super

kamehameha" action --> Fig.

$19 b$

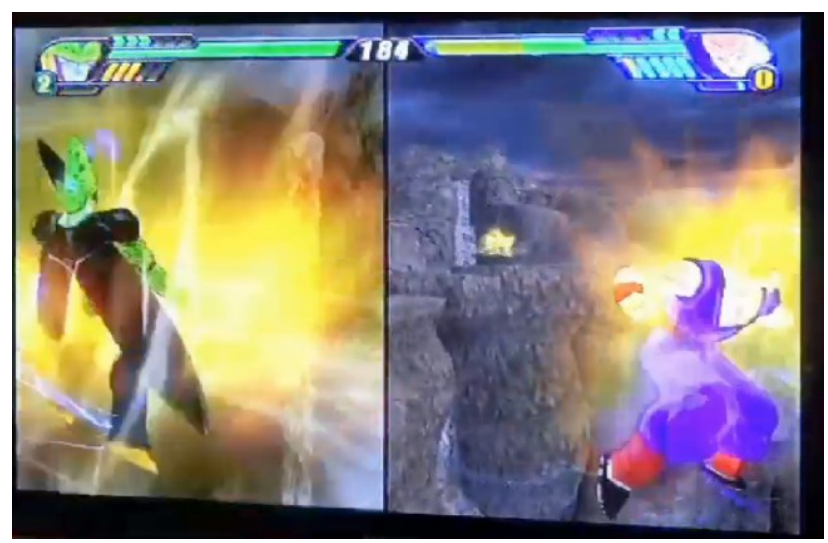

Figure 19a 


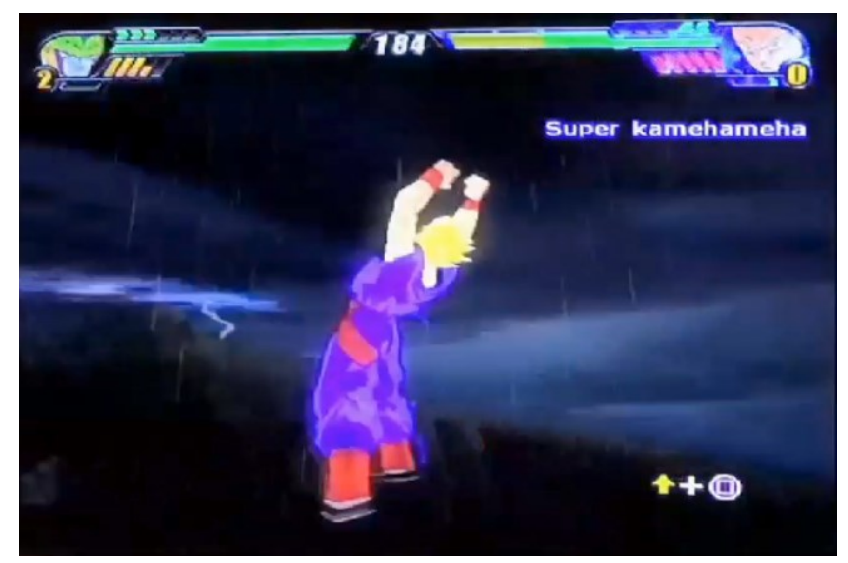

Figure 19b
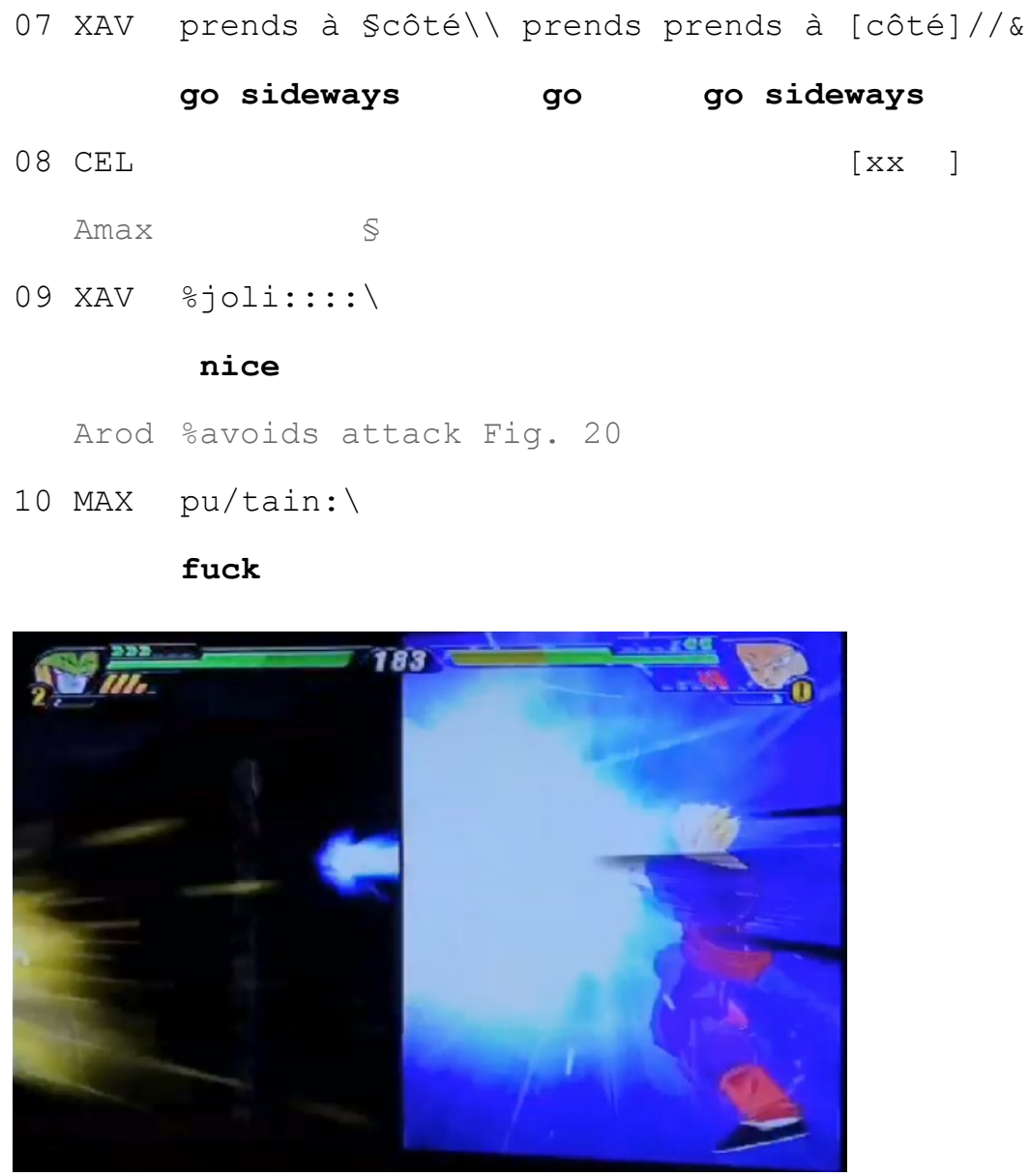

\section{Figure 20}

This preparation lasts nearly a second. During this time, Xav directly analyses the clues available on Rod's screen, he adjusts his instruction and explains to Rod that he is not using the correct button: he is using the "normal arrow" instead of pressing the "down arrow" button ("no here/ you (press) arrow/ uh:| normal here it's down arrow", 1.5-6). Rod then modifies his action on the controller. He stops his "super ray of death" action to get stronger (Fig. 19a), the 
split screen showing the two players' views switches to Max' screen and focuses on the preparation of his attack (III/ 00:02 to 00:07). Indeed, Max' avatar has finished his transformation and is now preparing an attack against Rod's avatar (the "super Kamehameha"; Fig. 19b). Once again, Xav directly analyses the information on Max' screen, and quickly proceeds with a new instruction addressed to Rod so that he can protect himself from the imminent attack: "move away quickly take aside take take aside" (1.6-7). Very quickly, Rod accomplishes the instructed action (Fig. 20) and avoids the attack. There is very little delay between Xav's instruction and Rod's execution on the controller and so, his avatar manages to avoid the attack. Xav assesses the result very positively with a prosodically marked "nice" (1.9) while Max assesses it negatively (l.10).

In contrast to what happens in extract 2 , where the three nonplayers laugh together, each non-player (Xav and Cel) focuses exclusively on the interaction with Rod - they do not interact together. Xav displays an obviously high engagement in the gaming activity through his provision of finely tuned technical instructions and positive assessments. Dom and Lea also gave very precise instructions and acknowledged the successful compliance to their instruction, but they always claimed non-seriousness. In this extract, Xav shows no claim of non-serious intent: He is entirely focused on the screen, with unchanging body posture and facial expressions - he does not laugh or smile. The players display seriousness in their gaming too, as indicated by their position, their facial expressions, and Max' negative assessment of Rod's successful counter.

With his serious instructions and assessments addressed to one of the two players, Xav accomplishes coaching actions (Partington/ Cushion 2013). This categorisation can be confirmed by the following turns: Xav turns back to Cel (Fig. 21) in response to his laughter (1.12). An ephemeral group of two is formed and Xav verbalises his self-categorisation as "coach" (1.13), to which Cel responds with laughter (1.14).

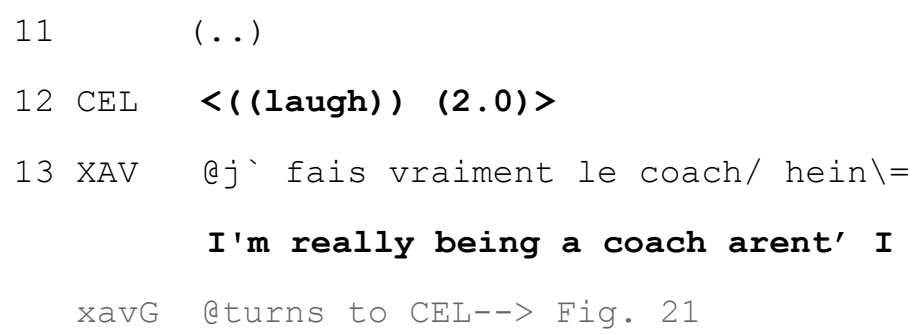




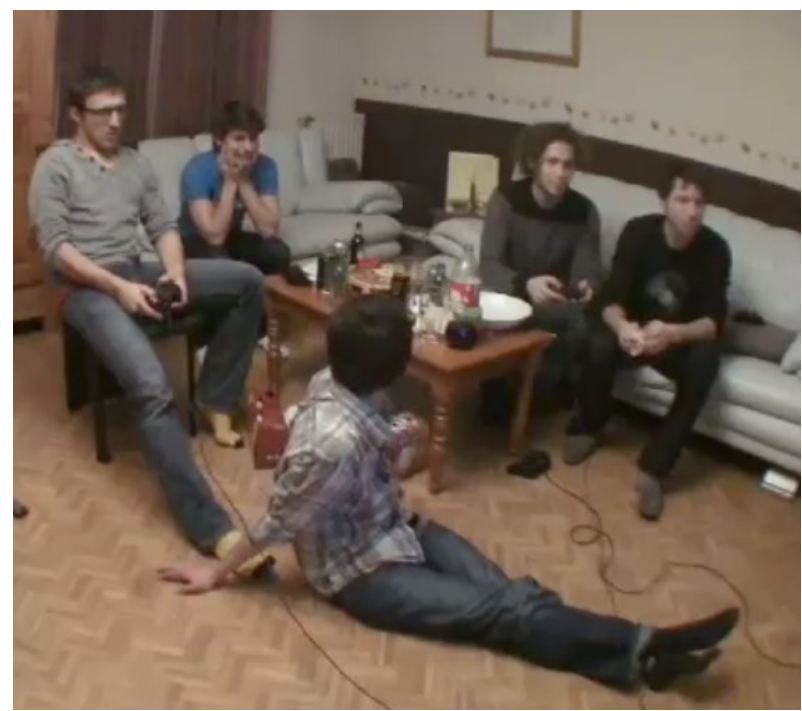

\section{Figure 21}

$14 \mathrm{CEL}=\langle(($ laugh $)) \quad(0.7)\rangle$

$15 \quad @(1.1)$

xavG eturns back to the screen-->>

$16 \mathrm{CEL}$ le mec en face/ il a trop la mort

the guy on the other side he's so dead

$17 ? \mathrm{xx}$

$18 \quad \#(1.9)$

scr \#max's health bar is lower

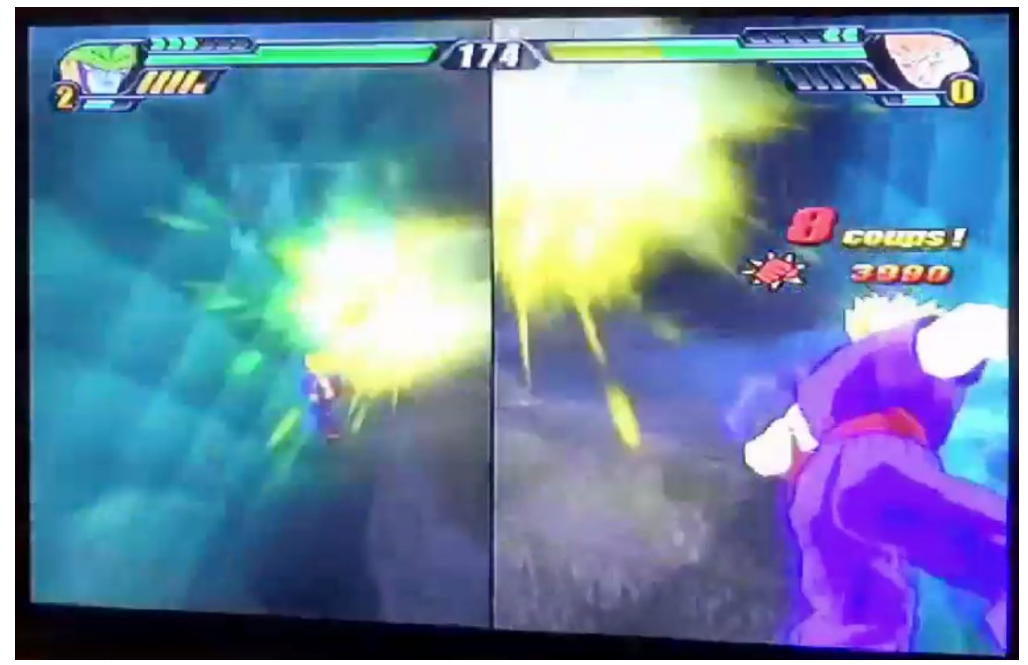

\section{Figure 22}

19 XAV allez max// (..) xx il a moins de vie//

come on max xx he has lower health 


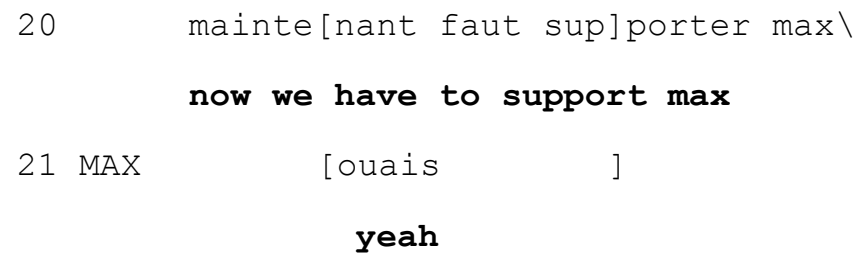

Even if Xav's self-categorisation is not explicitly confirmed by another participant, there are no signs of rejection or doubt. Besides, Cel's laugh line 14 could be understood as a form of acknowledgement.

Nevertheless, by turning back (Fig. 21) and looking at Cel who laughs right after the assessment turns, Xav creates an interactional space between Cel and himself. He shows his understanding of Cel's prior laughing (1.12) as a response to his prosodically marked assessment and as an invitation to open an encounter between the two of them. In a similar way to Lea and Vero in extract 2, Cel and Xav coconstruct an ephemeral group of spectators, excluding the others. Mondada (2013) pointed out how participants transit from one activity to another by reconfiguring the interactional space and modifying the participation framework. By turning back, Xav transits from the activity of "coaching" player Rod to initiating an exchange with non-player Cel about what he is doing. Although this ephemeral group lasts only 1.3 seconds, it provides an opportunity to report and negotiate different analyses of the game. ${ }^{13}$

Immediately after this short sequence among spectators, Xav turns back to the screen (1.15) and it becomes apparent that Max's avatar is losing health points (Fig. 22). Xav comments the new situation with an encouragement addressed to Max.

Interestingly, this encouragement of the player is followed by an explanation concerning the spectators' "strategy": now that Max' avatar has lower health (1.19), he needs to be supported (1.20). Supporting (and maybe coaching) a player fluctuates, depending on the players' situation in the game, and it is negotiated among spectators. Spectators become engaged participants in the game, interacting more or less constantly with the players, and additionally, they form ephemeral groups among themselves to exchange about positions and analyses. As spectators, they occupy a particular, proper role in the gaming interaction: they ensure the gaming's progress, excitement and fun.

13 This has been analysed by Mondada (2012) for gamers. Our analyses provide evidence that non-players act in a similar way. 


\subsection{Discussion}

The previous sections (5.1-5.3) have detailed different embodied practices used by the non-players/spectators which are related to the ways of spectating described in section 4: alternating engagement and disengagement, jocular mockery and coaching. It has also shown that spectators may not only interact with players, but also with other spectators, in different ways.

All described practices are characterized by a finely tuned temporal adjustment with regard to the gaming activities. This adjustment has already been described for the interaction among players (Mondada 2013), but it is also true of spectators, not only concerning instructions, proposals, assessments or encouragements addressed to players, but also concerning sequences among spectators.

Through gaze, body posture, monitoring or similar "scaffolding" actions (Tekin/Reeves 2017), spectators display a general interest in the gaming activities, which signals to players that they might recruit them for assistance. The alternation between engagement and disengagement can thus be seen as constant signs of "possible engagement”. Proposals, instructions, assessments, encouragements or other help offers are produced with regard to the temporality of the game and make a claim of knowledge which is negotiable. ${ }^{14} \mathrm{By}$ claiming and displaying expertise, spectators become co-players as they directly participate to the progression of the game's trajectories.

A large repertoire of multimodal resources is used to participate in different activities simultaneously. Sequences involving a spectator and a player are perceptible by other players and spectators who can join the interaction or who, as players, can adjust their gaming strategy to the strategies deployed in these sequences. Spectators may also guide the player and, at the same time, share their positions and analyses with other spectators using gaze, facial expressions, laughter etc. Through gaze and body posture, they construct overlapping interactional spaces which allow for participation in the gaming activity as well as forming ephemeral groups with other spectators.

In spectator-spectator interactions as well as in spectator-player interactions, spectators can claim more or less serious intent. Through jocular mockery as in extract 2, spectators indicate nonseriousness, to which players can respond in different ways. Coaching, as in extract 3, involves a more serious way of spectating. Nevertheless, by transferring their support to another player depending on

14 Even if all our extracts in this paper show an acceptance on the players' part, we could also observe rejections elsewhere in our data. 
the progression in the game, spectators also show that their coaching is less serious than coaching in sports interaction (cf. Colón de Carvajal 2016).

If our focus is on non-players/spectators, the detailed sequential and multimodal analyses indicate that spectating and non-players' engagement in the gaming activities is co-constructed. Players can simply accept the assistance offered by spectators and follow their instructions, acknowledge their claim of knowledge (see OlbertzSiitonen et al. in this issue), or display efforts to continue playing in their (own) way. They might also recruit the assistance of spectators, through trouble alerts, embodied displays of trouble, or requests. Even if they do not explicitly display trouble, they can show their needs by accepting a generic help offer for instance: in extract 3 , Max accepts Xav's offer to support him from now on, effectively recruiting him for further assistance in the game activity.

Players can become the object of spectators' interaction, as in the case of jocular mockery in extract 2. In that case, they are not expected to respond directly, but they might still take part in the interaction by accepting the moral implications (Haugh 2016) and joining the laughter or not.

\section{Conclusion}

While the organisation of participation in videogaming has already been analysed as far as the players' actions are concerned (cf. Keating/Sunakawa 2010; Piirainen-Marsh 2012; Mondada 2012; Baldauf-Quilliatre/Colón de Carvajal 2020), less research has focused on co-present non-players/spectators and their participation in the gaming activities (but see Tekin/Reeves 2017). The aim of our paper was to bridge this gap and describe three different "ways of spectating", namely, spectating related to doing being a couple, doing being friends, and doing being a supporter. These three ways of spectating correspond to specific realities, such as the number of participants (players and non-players) and their relations prior to this interaction, the type of game, the spatial configuration in the room etc., but they are above all practices which are locally accomplished and interactionally negotiated. Our argumentation has been twofold: on the one hand, describing these three ways of spectating, and on the other hand, describing a selection of embodied practices used to achieve them.

By bringing into focus these practices, we want to highlight the interactional and multimodal accomplishment of spectatorship. In other words, it might be possible to categorise players and non-play- 
ers in videogame interactions, but being a spectator cannot be defined in this way. The role of a spectator is complex, as different ways of spectating are co-constructed by all participants, related to the ecological context in a way which is far from straightforward.

\section{Acknowledgement}

The authors are grateful to the ASLAN project (ANR-10-LABX0081) of Université de Lyon, for its financial support within the program "Investissements d'Avenir" (ANR-11-IDEX-0007) of the French government operated by the National Research Agency (ANR). Many thanks to Florence Oloff and Elizabeth Keating whose very valuable comments helped to improve a prior version of this paper.

\section{Appendix}

Conventions for verbal transcription: ICOR Convention ${ }^{15}$

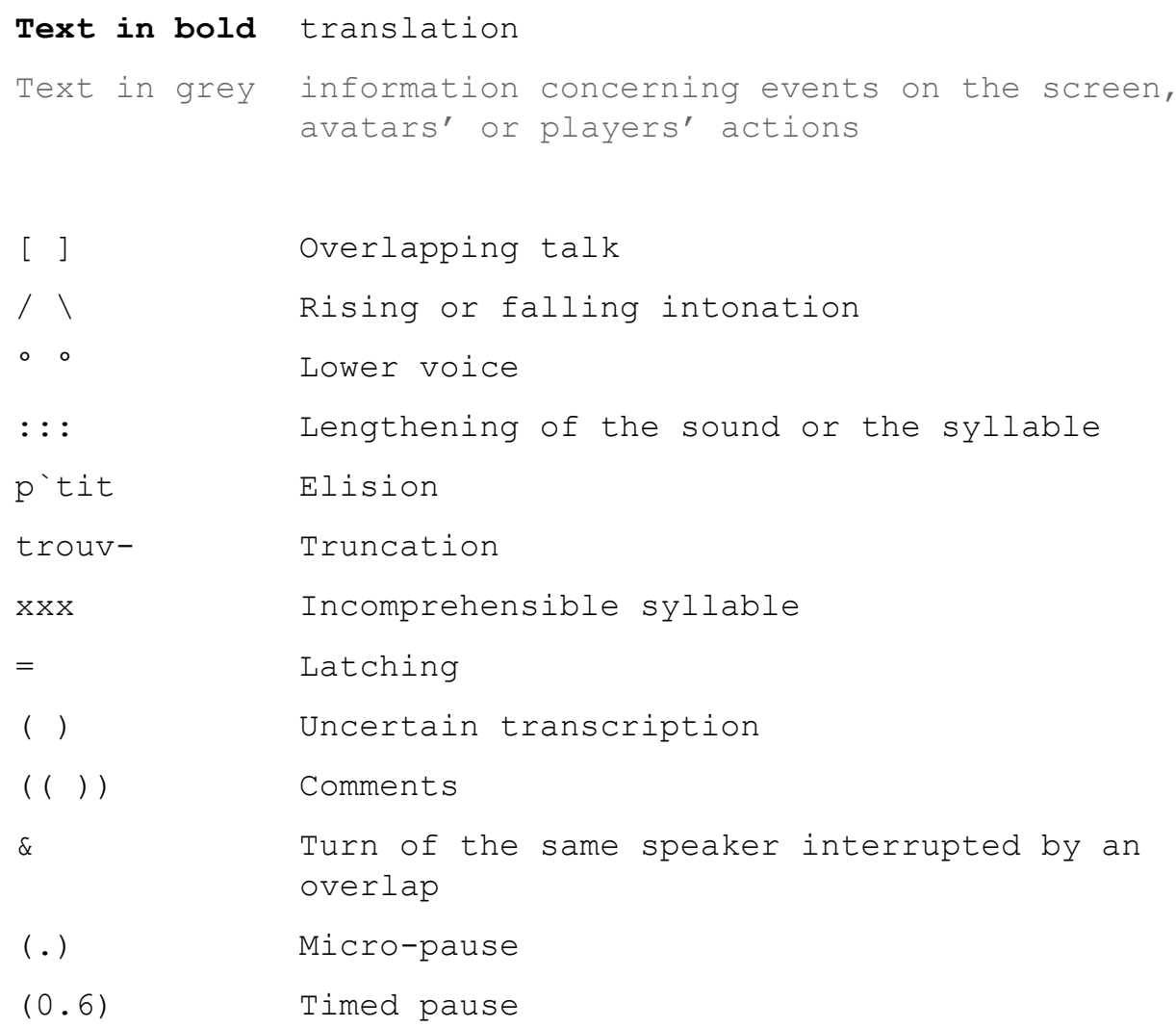

15 See: http://icar.univ-

lyon2.fr/projets/corinte/bandeau_droit/convention_icor.htm 
Multimodal convention (Mondada 2018): ${ }^{16}$

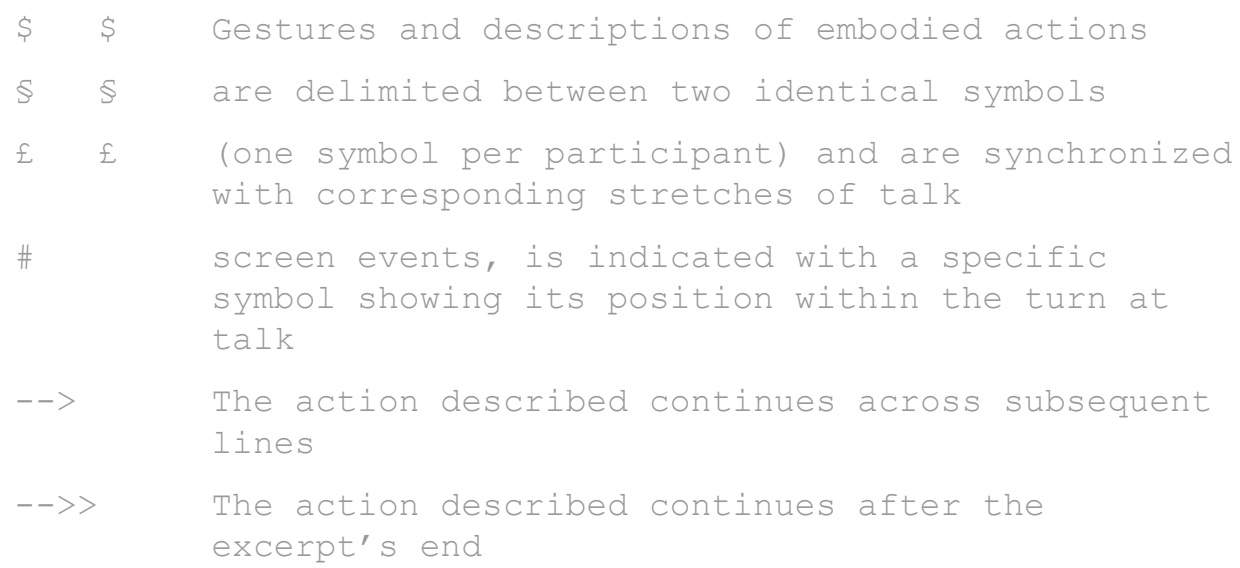

\section{Bibliography}

Baldauf-Quilliatre, Heike/Colón de Carvajal, Isabel (2015): Is the avatar considered as a participant by the players? A conversational analysis of multi-player videogames interactions. In: PsychNology Journal 13 (2-3), 127-147.

Baldauf-Quilliatre, Heike/Colón de Carvajal, Isabel (2019): Interaktionen bei Videospiel-Sessions: Interagieren in einem hybriden Raum. In: Marx, Konstanze/Schmidt, Axel (eds.): Interaktion und Medien. Interaktionslinguistische Zugänge zu medienvermittelter Kommunikation. Heidelberg: Winter, 219-256.

Baldauf-Quilliatre, Heike/Colón de Carvajal, Isabel (2020): Encouragement in videogame interactions. In: Social Interaction. Video-Based Studies of Human Sociality 2 (2), DOI: https://doi.org/10.7146/si.v2i2.118041.

Baldauf-Quilliatre, Heike/Colón de Carvajal, Isabel (in press): Multimodal practices of participation in a complex and dynamic participation framework. In: Basso-Fossali, Pierluigi et al. (eds.): Complexity in interaction. Berlin: Language Science Press.

Bell, Allan (1984): Language style as audience design. In: Language and Society 13, 145-204.

Christmann, Gabriela (1996): Die Aktivität des 'Sich Mokierens' als konversationelle Satire. Wie sich Umweltschützer/innen über den 'Otto-Normalverbraucher' mokieren. In: Kotthoff, Helga (ed.): Scherzkommunikation. Opladen: Westdeutscher Verlag, 49-80.

16 See: https://franzoesistik.philhist.unibas.ch/fileadmin/user_upload/ franzoesistik/mondada_multimodal_conventions.pdf 
Colón De Carvajal, Isabel (2016): Désaccord entre joueurs dans les jeux vidéo: vraie discorde ou fausse compétition? In: Cahiers de Praxématique [en ligne] 67, 1-18. https://doi.org/10.4000/praxematique.4434.

De Stefani, Elwys (2014): Establishing joint orientation towards commercial objects in a self-service store. In: Nevile, Maurice et al. (eds.): Interacting with objects: language, materiality and social activity, Amsterdam, Philadelphia: Benjamins, 271-293.

Downs, John et al (2014): Audience Experience in Social Videogaming: Effects of Turn Expectation and Game Physicality. CHI 2014, Toronto, DOI: http://dx.doi.org/10.1145/2556288.2556965.

Dynel, Marta (2011): "You talking to me?" The viewer as a ratified listener to film discourse. In:Journal of Pragmatics 43, 1628-1644.

Dynel, Marta (2014): On the part of ratified participants: ratified listeners in multi-party interactions. In: Brno Studies in English, 40 (1), 27-44. DOI: 10.5817/BSE2014-1-2.

Garfinkel, Harold (1967): Studies in Ethnomethodology. Cambridge: Polity Press.

Gerhardt, Cornelia (2006): Moving Closer to the Audience: Watching Football on Television. In: Revista Alicantina de Estudios Ingleses 19, 125-148.

Goffman, Erving (1981): Forms of Talk. Philadelphia: University of Pennsylvania Press.

Goodwin, Charles (2007): Participation, stance and affect in the organisation of activities. In: Discourse E Society 18 (1), 53-73. DOI 10.1177/0957926507069457.

Goodwin, Charles/Goodwin, Marjorie (1996): Seeing as a Situated Activity: Formulating Planes. In: Engeström, Yrjo/Middleton, David (eds.): Cognition and Communication at Work. Cambridge, Cambridge University Press, 61-95.

Goodwin, Charles/Goodwin, Marjorie (2004): Participation. In: Duranti, Alessandro (ed.): A companion to linguistic anthropology. Oxford: Basil Blackwell, 222-234.

Günthner, Susanne (1996): Zwischen Scherz und Schmerz - Frotzelaktivitäten in Alltagsinteraktionen. In: Kotthoff, Helga (ed.): Scherzkommunikation. Opladen: Westdeutscher Verlag, 81-108.

Haugh, Michael (2014): Jocular Mockery as Interactional Practice in Everyday Anglo-Australian Conversation. In: Australian Journal of Linguistics 34 (1), 76-99, DOI: 10.1080/07268602.2014.875456.

Haugh, Michael (2016):“Just kidding": Teasing and claims to nonserious intent. In: Journal of Pragmatics 95, 120-136.

Heritage, John (2012): The Epistemic Engine: Sequence Organization and Territories of Knowledge. In: Research on Language and Social Interaction 45 (1), 30-52, DOI: 10.1080/08351813.2012. 646685. 
Heritage, John (2013): Action formation and its epistemic (and other) backgrounds. In: Discourse Studies 15 (5), 551-578, DOI: 10.1177| 1461445613501449.

Hoey, Elliott (2020): When Conversation Lapses: The Public Accountability of Silent Copresence. Oxford: Oxford University Press.

Holly, Werner/Baldauf, Heike (2001): Grundlagen des fernsehbegleitenden Sprechens. In: Holly, Werner/Püschel, Ulrich/Bergmann, Jörg (eds.): Der sprechende Zuschauer. Wie wir uns Fernsehen kommunikativ aneignen. Opladen: Westdeutscher Verlag, 41-60.

Holly, Werner/Püschel, Ulrich/Bergmann, Jörg (eds.) (2001): Der sprechende Zuschauer. Wie wir uns Fernsehen kommunikativ aneignen. Opladen: Westdeutscher Verlag.

Isep, Claudia (2014): Paar-Sein in Interaktion beforschen. Methodologische Überlegungen zu einer Synthese von Konversationsanalyse und Ethnographie. In: Schwarze, Cordula/Konzett, Carmen (eds.): Interaktionsforschung: Gesprächsanalytische Fallstudien und Forschungspraxis. Berlin: Frank \& Timme, 131-153.

Kaytoue, Mehdi et al (2012): Watch me playing. I am a professional: A first study on video game live streaming. In: Proceedings of $W W W 2012,1181-1188$. DOI: $10.1145 / 2187980.2188259$.

Keating, Elizabeth/Sunakawa, Chiho (2010): Participation cues: Coordinating activity and collaboration in complex online gaming worlds. In: Language in Society 39 (3), 331-356.

Kendrick, Kobin/Drew, Paul (2016): Recruitment: Offers, Requests, and the Organization of Assistance in Interaction. In: Research on Language and Social Interaction 49 (1), 1-19. DOI: 10.1080/ 08351813.2016.1126436.

Klemm, Michael (2000): Zuschauerkommunikation. Formen und Funktionen der alltäglichen kommunikativen Fernsehaneignung. Frankfurt et al.: Lang.

Laurier, Eric (2019): The panel show: further experiments with graphic transcripts and vignettes. In: Social Interaction. VideoBased Studies of Human Sociality, 2, 1. DOI 10.7146/si.v2i1. 113968.

Licoppe, Christian (2014): Contested norms of presence. In: Hahn, Kornelia/Stempfhuber, Martin (eds.): Präsenzen 2.0. Körperinszenierung in Medienkulturen. Wiesbaden: Springer, 97-112.

Lin, Holin/Sun, Chuen Tsai (2011): The role of onlookers in arcade gaming: Frame analysis of public behaviours. In: Convergence, 17(2), S. 125-137. 
Mondada, Lorenza (2012): Coordinating action and talk-in-interaction in and out of video games. In: Ayass, Ruth/Gerhardt, Cornelia (eds.): The appropriation of media in everyday life, Amsterdam, Philadelphia: Benjamins, 231-270.

Mondada, Lorenza (2013): Coordinating mobile action in real time: The timely organization of directives in video games. In: Haddington, Pentti/Mondada, Lorenza/Nevile, Maurice (eds.): Interaction and mobility: Language and the body in motion. Berlin, New York: de Gruyter, 300-341.

Mondada, Lorenza (2018): Multiple Temporalities of Language and Body in Interaction: Challenges for Transcribing Multimodality. In: Research on Language and Social Interaction 51 (1), 85-106. DOI: $10.1080 / 08351813.2018 .1413878$.

Mondada, Lorenza (2019a): Contemporary issues in conversation analysis: Embodiment and materiality, multimodality and multisensoriality in social interaction. In: Journal of Pragmatics 145, 47-62.

Mondada, Lorenza (2019b): Transcribing silent actions: a multimodal approach of sequence organization. In: Social Interaction. VideoBased Studies of Human Sociality 2 (1) DOI: 10.7146/si.v2i1.113150.

Nishizaka, Aug (2000): Seeing What One Sees: Perception, Emotion, and Activity. In: Mind, Culture, and Activity 7 (1\&2), 105-123.

Olbertz-Siitonen, Margarethe/Piirainen-Marsh, Arja/Siitonen, Marko (in this issue): Co-constructing presence through shared VR gameplay.

Partington, Mark/Cushion, Christopher (2013): Performance during performance: using Goffman to understand the behaviours of elite youth football coaches during games. In: Sports Coaching Reviere 1-2, 93-105.

Piirainen-Marsh, Arja (2012): Organising participation in video gaming activities. In: Ayass, Ruth/Gerhardt, Cornelia (eds.): The appropriation of media in everyday life, Amsterdam, Philadelphia: Benjamins, 197-230.

Recktenwald, Daniel (2017): The Discourse of Online Live Streaming on Twitch: Communication between Conversation and Commentary, PHD Thesis, Hong Kong Polytechnic University.

Reeves, Stuart/Greiffenhagen, Christian/Laurier, Eric (2017): Video gaming as practical accomplishment: Ethnomethodology, conversation analysis, and play. In: Topics in Cognitive Science 9 (2), 308-342.

Reynolds, Edward (2017): Description of membership and enacting membership: Seeing-a-lift, being a team. In: Journal of Pragmatics 118, 99-119.

Schegloff, Emanuel/Sack, Harvey (1973): Opening up closings. In: Semiotica 8 (4) 289-327. 
Schmidt, Axel/Marx, Konstanze (2020): Making let's play watchable. An interational approach to gaming visualization. In: Thurlow, Crispin/Dürscheidt, Christa/Diémoz, Federica (eds.): Visualizing digital discourse. Interactional, institutional and ideological perspectives. Berlin, New York: de Gruyter, 131-150.

Schmitt, Reinhold (2016): Der „Frame-Comic “als Dokument multimodaler Interaktionsanalysen. In Hausendorf, Heiko/Schmitt, Reinhold/Kesselheim, Wolfgang (eds.): Interaktionsarchitektur, Sozialtopographie und Interaktionsraum, Tübingen: Narr, 189226.

Sidnell, Jack/Stivers, Tanya (eds.) (2013): The handbook of conversation analysis. Malden, Oxford: Blackwell.

Tekin, Burak/Reeves, Stuart (2017): Ways of spectating: Unravelling spectator participation in Kinect play. CHI 2017, Denver, DOI: 10.1145/3025453.3025813.

Wenger, Etienne (1998): Communities of practice: Learning as a social system. In: Systems thinker 9 (5), 1-10. URL: https://participativelearning.org/pluginfile.php/636/mod_resour ce/content/3/Learningasasocialsystem.pdf. 